\title{
Lethal T cell immunodeficiency induced by chronic costimulation via CD27-CD70 interactions
}

Kiki Tesselaarr,2,*, Ramon Arens ${ }^{1-3, *}$, Gijs M.W. van Schijndel², Paul A. Baars ${ }^{1,2}$, Martin A. van der Valk ${ }^{4}$, Jannie Borst ${ }^{5}$, Marinus H.J. van Oers ${ }^{3}$ and René A.W. van Lier ${ }^{1,2}$

Published online 9 December 2002; doi:10.1038/ni869

It has been proposed that HIV-I, in addition to directly infecting and killing CD4+ $\mathrm{T}$ cells, causes $\mathrm{T}$ cell dysfunction and $T$ cell loss by chronic immune activation. We analyzed the effects of chronic immune activation in mice that constitutively expressed CD70, the ligand for the tumor necrosis factor receptor family member CD27, on B cells. CD70 transgenic (CD70 Tg) mice showed a progressive conversion of naive $T$ cells into effector-memory cells, which culminated in the depletion of naive $T$ cells from lymph nodes and spleen. T cell changes depended on continuous CD27-CD70 interactions and $\mathrm{T}$ cell antigen receptor stimulation. Despite this hyperactive immune system, CD70 Tg mice died aged 6-8 months from Pneumocystis carinii infection, a hallmark of $T$ cell immunodeficiency. Thus, persistent delivery of costimulatory signals via CD27-CD70 interactions, as may occur during chronic active viral infections, can exhaust the $T$ cell pool and is sufficient to induce lethal immunodeficiency.

The outcome of adaptive immune reactions depends on interactions between an abundance of cell surface receptors on lymphocytes and their cognate ligands ${ }^{1}$. These receptor-ligand systems not only control the size of the expanded antigen-specific lymphocyte pool but also its effector functions and migratory potential. Receptors fall into distinct protein families - such as the immunoglobulin supergene family and the cytokine receptor superfamily - and signaling outcome is largely dictated by evolutionarily conserved signaling domains, located in their cytoplasmic portions. Cellular responses after receptor triggering depend on other receptors that are ligated in series, and/or in parallel, and the strength and duration of receptor-ligand interactions. Therefore, the coordination of immune reactions relies highly on the regulated expression of genes encoding relevant receptors and ligands.

The tumor necrosis factor receptor (TNFR) family is a group of type I transmembrane molecules that share sequence homology in their cysteine-rich, extracellular, ligand-binding domains. Based on their cytoplasmic sequences, TNFR family members can be divided into two classes. Receptors that contain a death domain can convey an apoptotic signal $^{2}$, whereas receptors that contain a TNFR-associated factor (TRAF)-binding domain regulate diverse immunological processes a

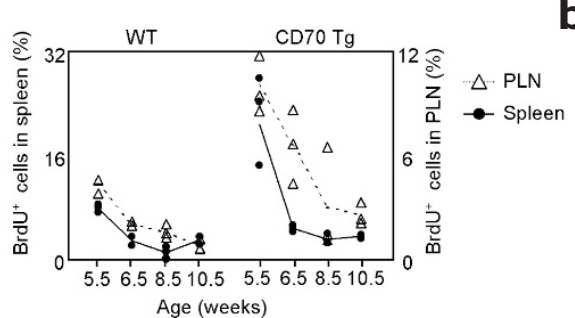

b

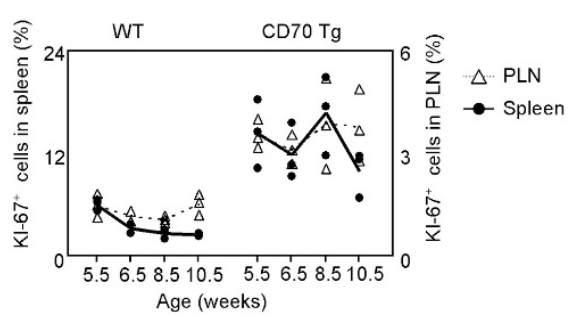

C

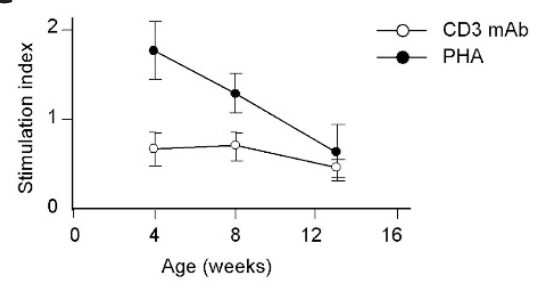

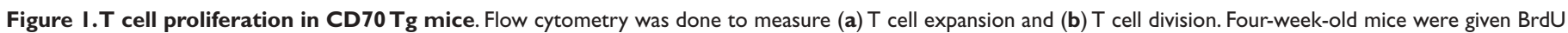

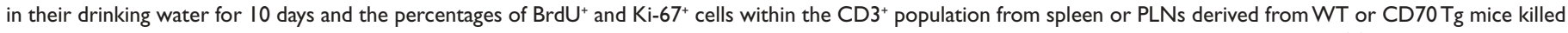

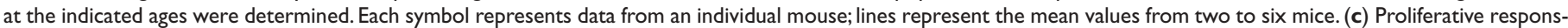

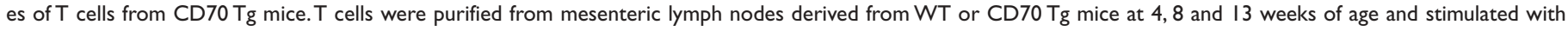

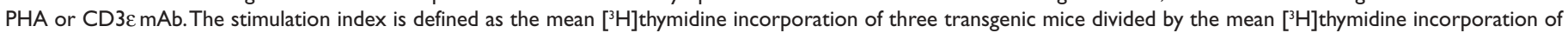

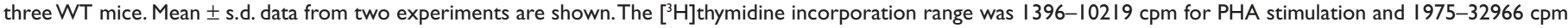
for CD3 mAb stimulation.

'Laboratory for Experimental Immunology and ${ }^{3}$ Department of Hematology, Academic Medical Center, P.O. Box 22700, I I00DD Amsterdam, The Netherlands. ${ }^{2}$ Department of Immunobiology, Sanquin/Research and Landsteiner Laboratory of the Academic Medical Center, Plesmanlaan I25, 1066CX Amsterdam, The Netherlands. ${ }^{4}$ Laboratory of Experimental Animal Pathology and ${ }^{5}$ Division of Cellular Biochemistry, The Netherlands Cancer Institute, Plesmanlaan I2I, I066CX Amsterdam, The Netherlands. *These authors contributed equally to this work. Correspondence should be addressed to R.A.W.v.L. (R.vanLier@AMC.UVA.NL). 
a
C

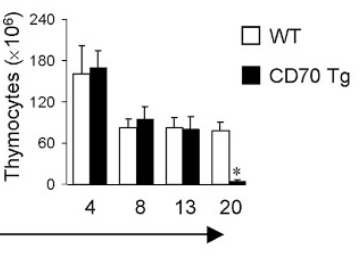

Figure 2.T cell cellularity and phenotype in CD70 Tg mice. Absolute numbers of CD3 ${ }^{+} T$ cells in (a) spleen and (b) PLNs from WT and CD70 Tg mice aged $4,8,13$ and 20 weeks were determined. T cell numbers were calculated by multiplying the number of mononuclear cells with the percentage of $C D 3^{+} T$ cells, as determined by flow cytometry. (c) Thymic cellularity was determined by counting lymphocyte numbers of WT and CD70 Tg mice at the indicated ages. Mean \pm s.d. data from four to six mice are shown. Differences between the mean values for WT and CD70 Tg at the indicated ages were considered significant $(*)$ if $P<0.05$ (by Student's $t$-tests). (d) Phenotypes of $\mathrm{CD}^{+}$and $\mathrm{CD} 8^{+}$splenic $T$ cells determined by flow cytometry. Naive $T$ cells were defined as $C D 44^{\text {negllo }} \mathrm{CD} 62 \mathrm{~L}^{\text {hi; }}$ effector-memory cells were defined as $C D 44^{\text {hi }} C D 62 \mathrm{~L}^{\text {neg. }}$. The percentages of cells in each quadrant are indicated.

including proliferation, survival, effector function and migration ${ }^{3,4}$ Although a number of TNFR molecules bind similar TRAF molecules, gene knock-out strategies have revealed distinct, nonredundant roles for individual molecules in regulating $\mathrm{T}$ cell immunity. OX $40^{-/-}$mice and OX40L $\mathrm{L}^{-1-}$ mice show impeded $\mathrm{CD}^{+} \mathrm{T}$ cell responses, which is reflected in a poor delayed-type hypersensitivity response ${ }^{5,6}$. In contrast, $4-1 \mathrm{BB}^{-}$ mice show impaired $\mathrm{CD}^{+} \mathrm{T}$ cell responses to viral pathogens ${ }^{7}$, whereas in $\mathrm{CD} 27^{-/}$animals, both $\mathrm{CD}^{+}$and $\mathrm{CD}^{+} \mathrm{T}$ cell responses are reduced after influenza virus challenge ${ }^{8}$. In part, these differences might originate from the distinct expression patterns of these receptors.

In addition to these loss-of-function mutations, which highlight the biological relevance of TNFR family members, several gain-of-function mutations have shown that receptor signaling needs to be limited to maintain homeostasis within the immune system. In humans, recessive mutations in the extracellular portion of TNFR type I have been identified that prevent physiological receptor cleavage. The inability to desensitize this receptor leads to a clinical syndrome with periods of fever and serositis ${ }^{9}$. In mice, targeted expression of TNF to the synovium is sufficient to induce arthritis, whereas transgenic ( $\mathrm{Tg}$ ) expression of TNF in the $\beta$ cells in the pancreas contributes to the breakdown of tolerance to these cells and finally to diabetes ${ }^{10}$. Constitutive expression of BAFF (B cell-activating factor belonging to the TNF family) induces B cell hyperactivation and a systemic lupus-like syndrome ${ }^{11}$. The CD27 ligand CD70 is an activation molecule that is predominantly expressed on stimulated lymphocytes after antigenic stimulation ${ }^{12-14}$. a

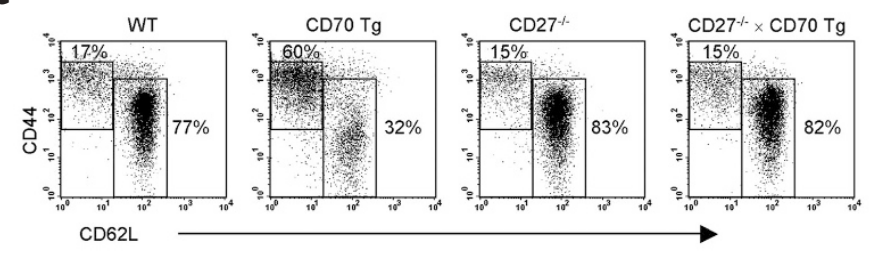

d

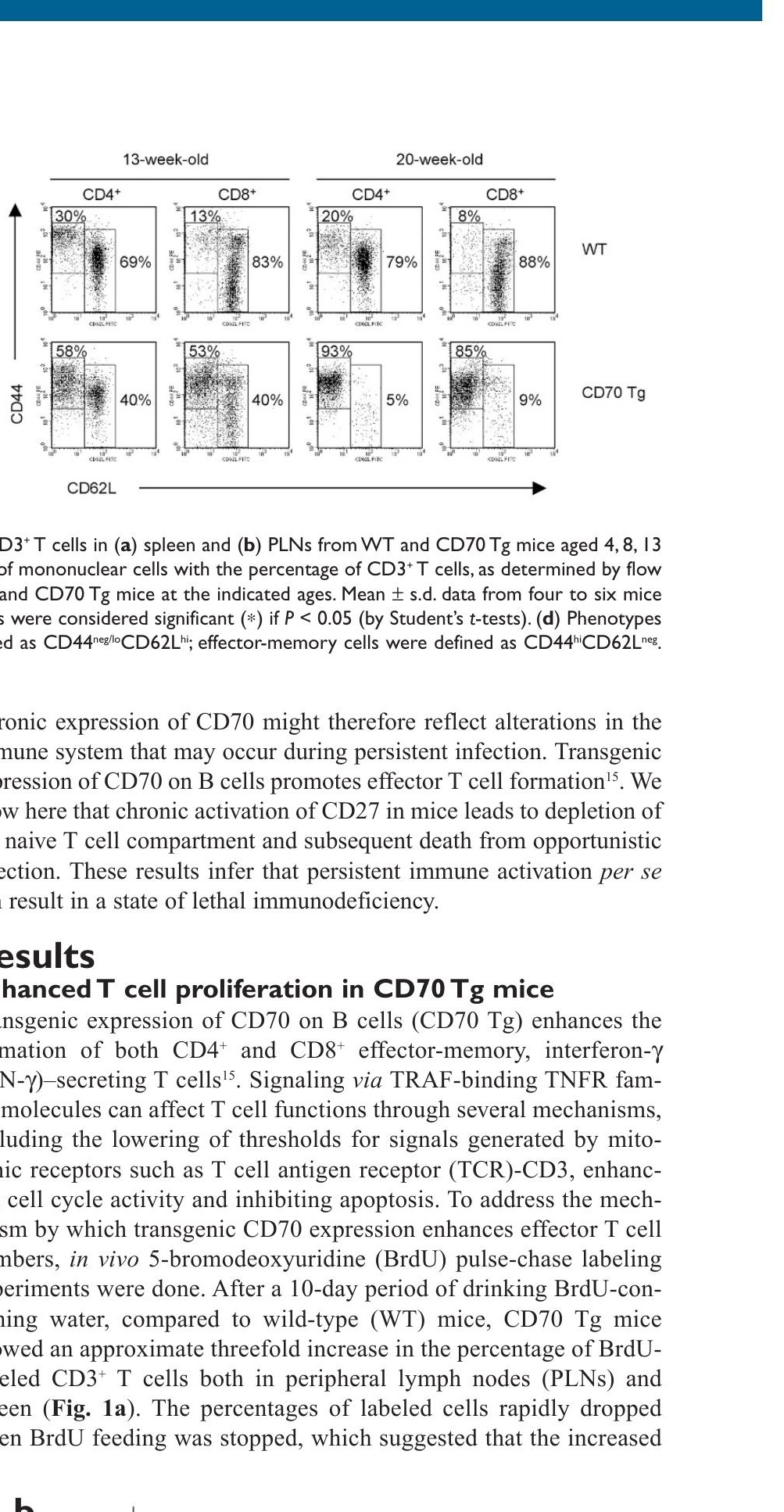

CD
CD62L

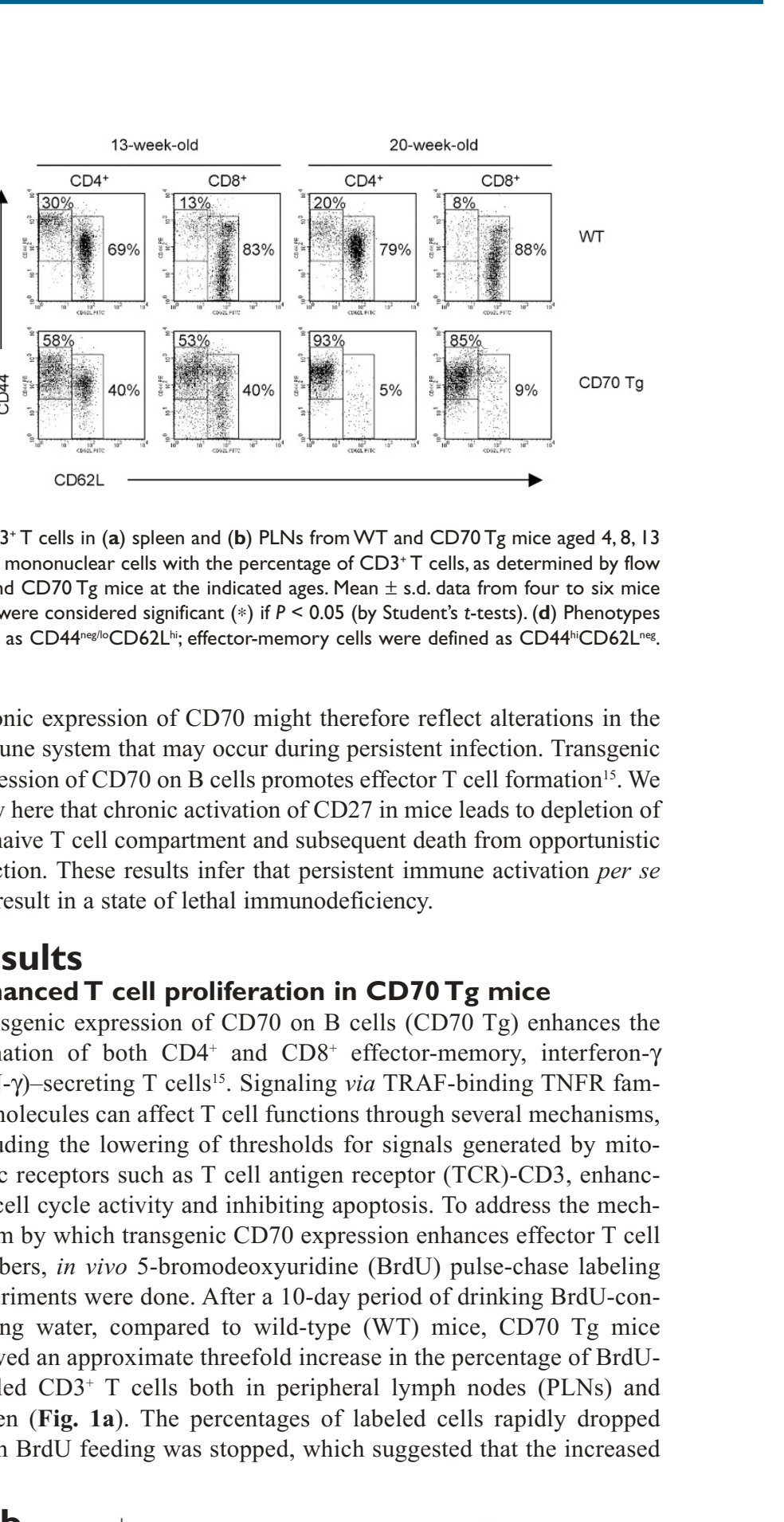

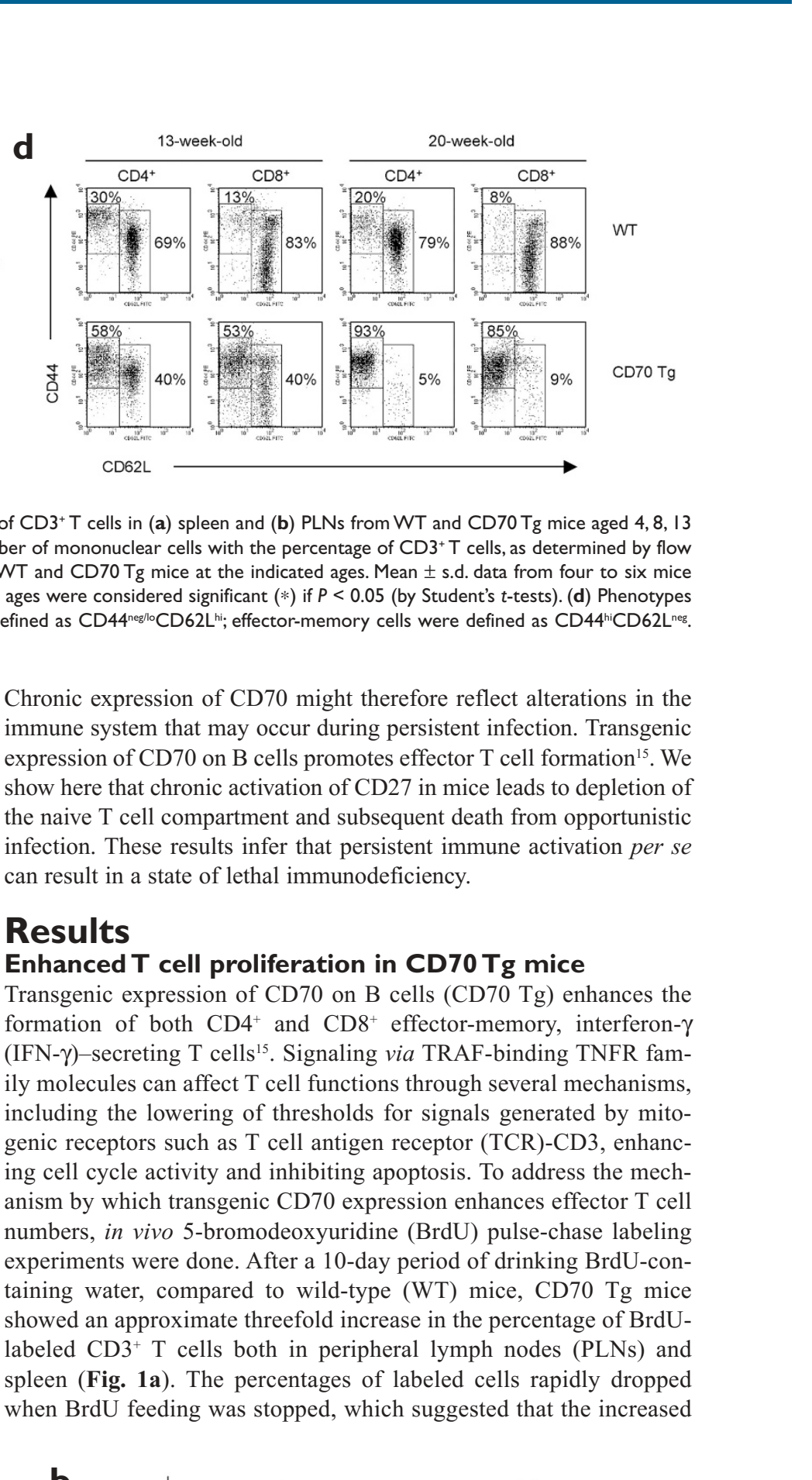

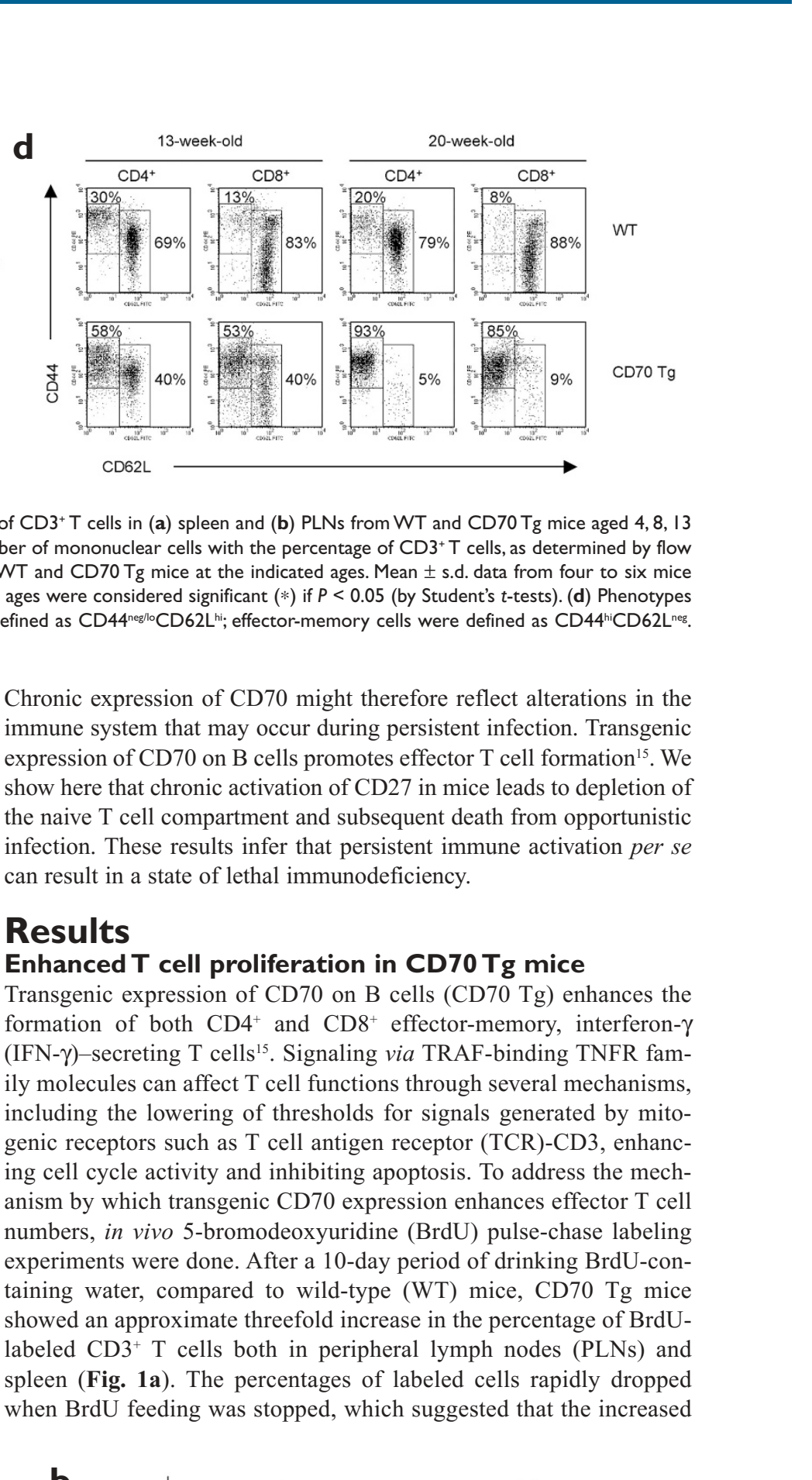

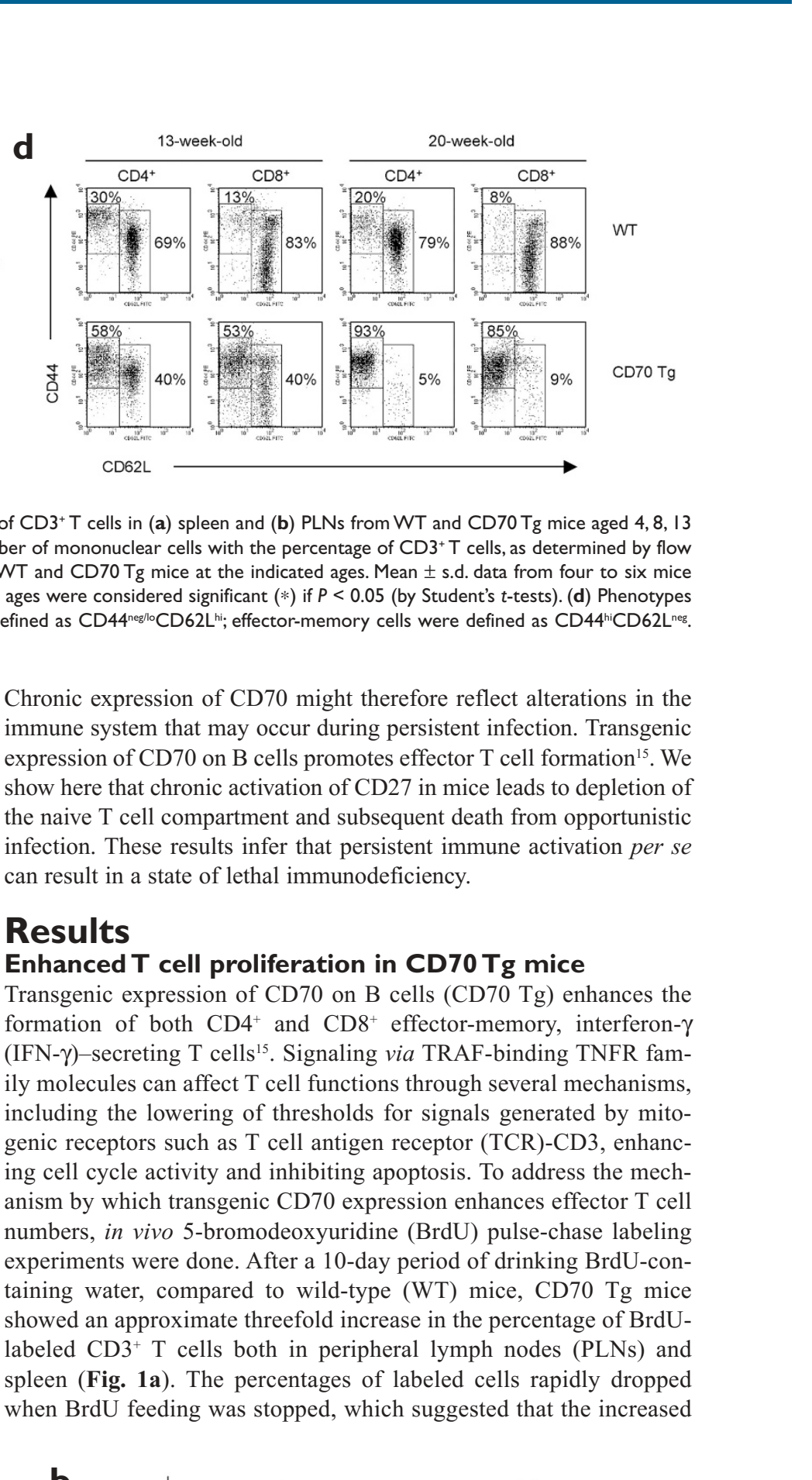

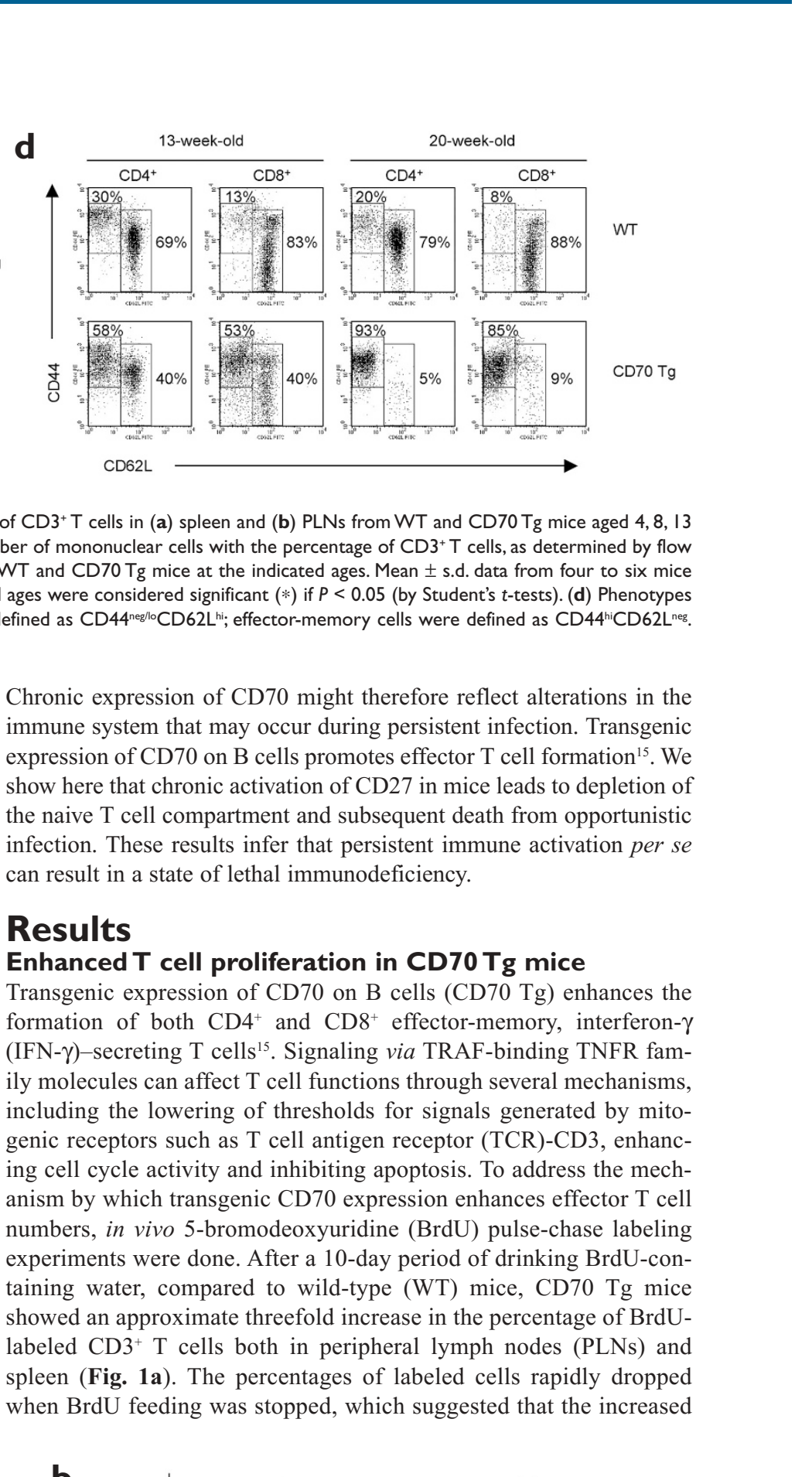

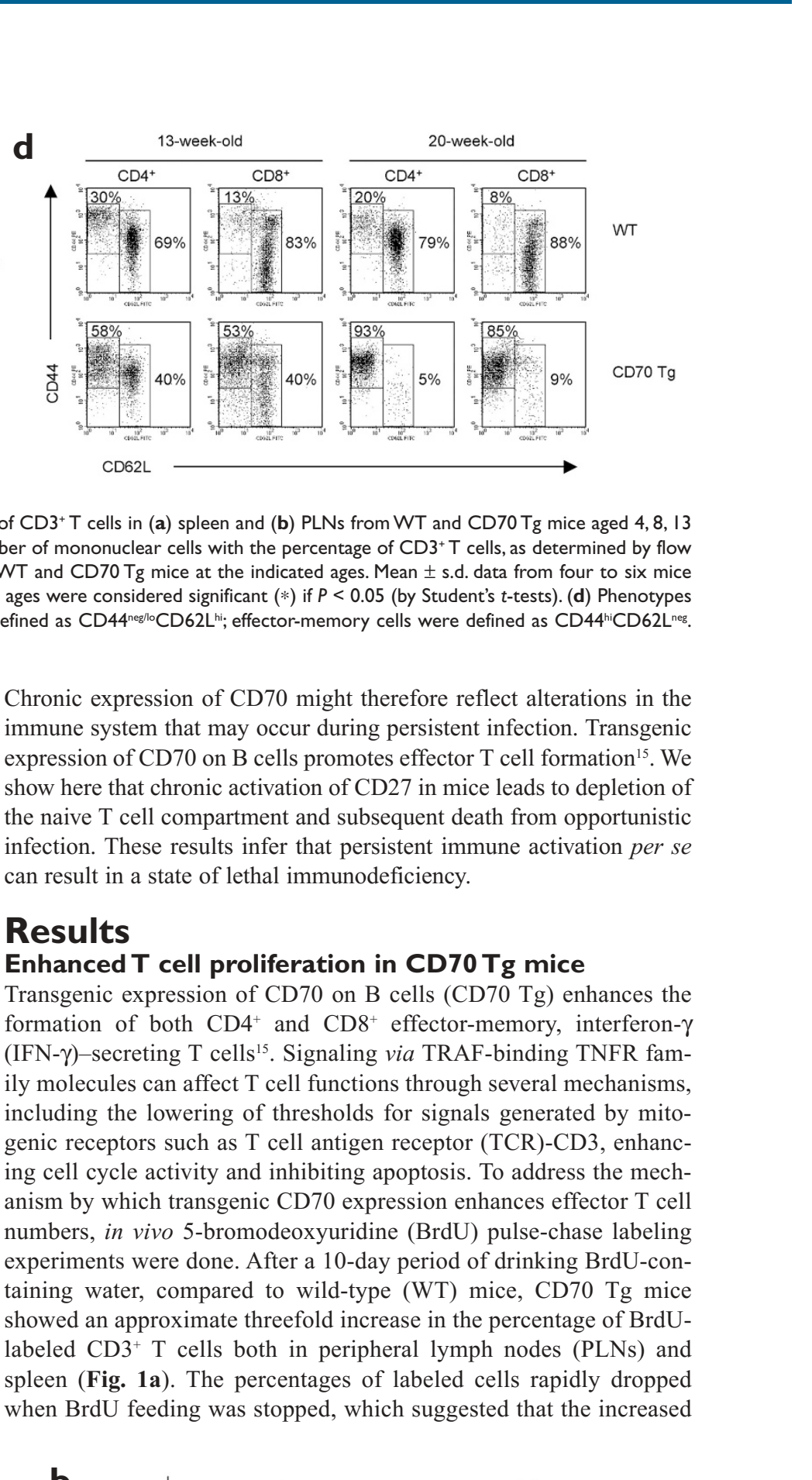

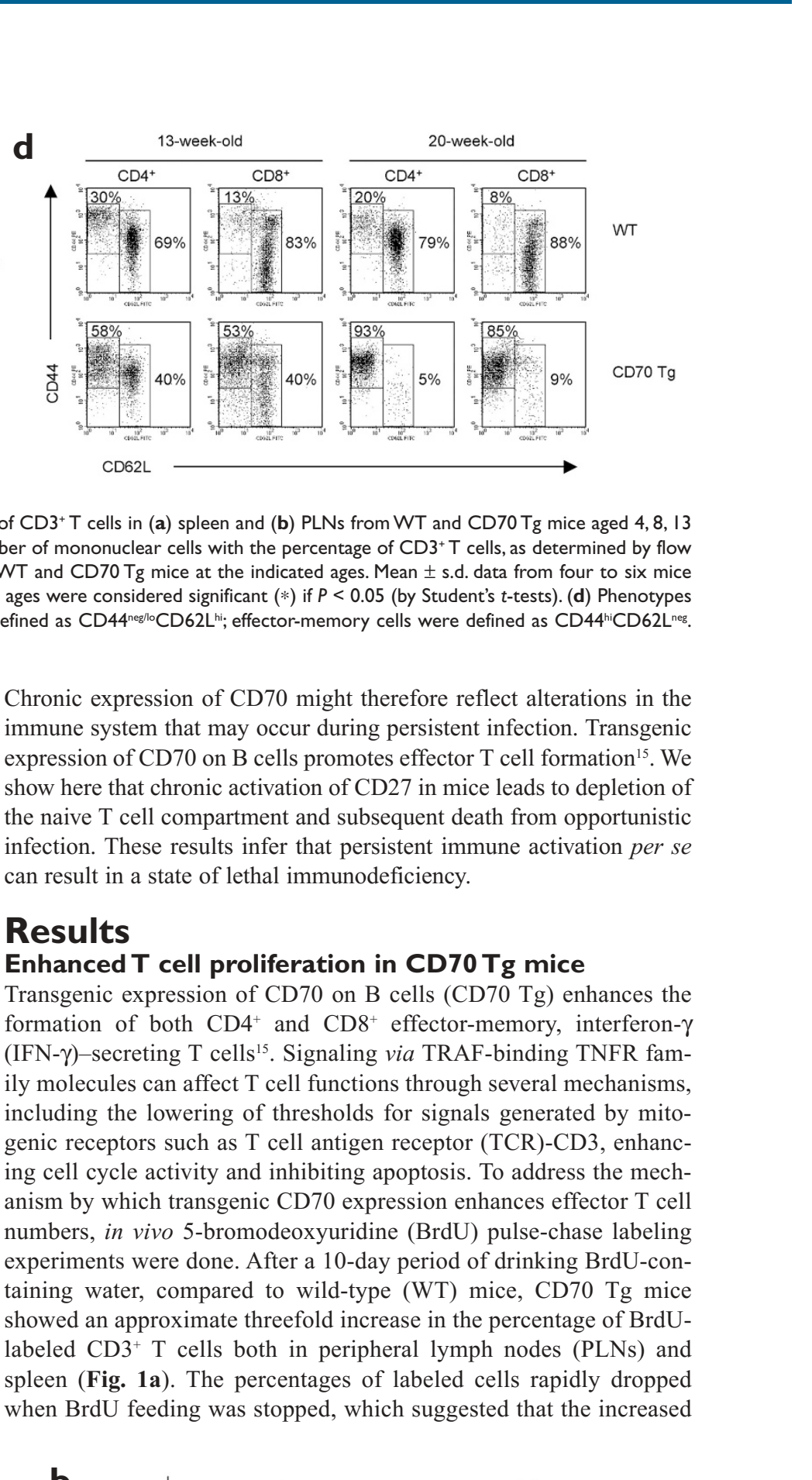

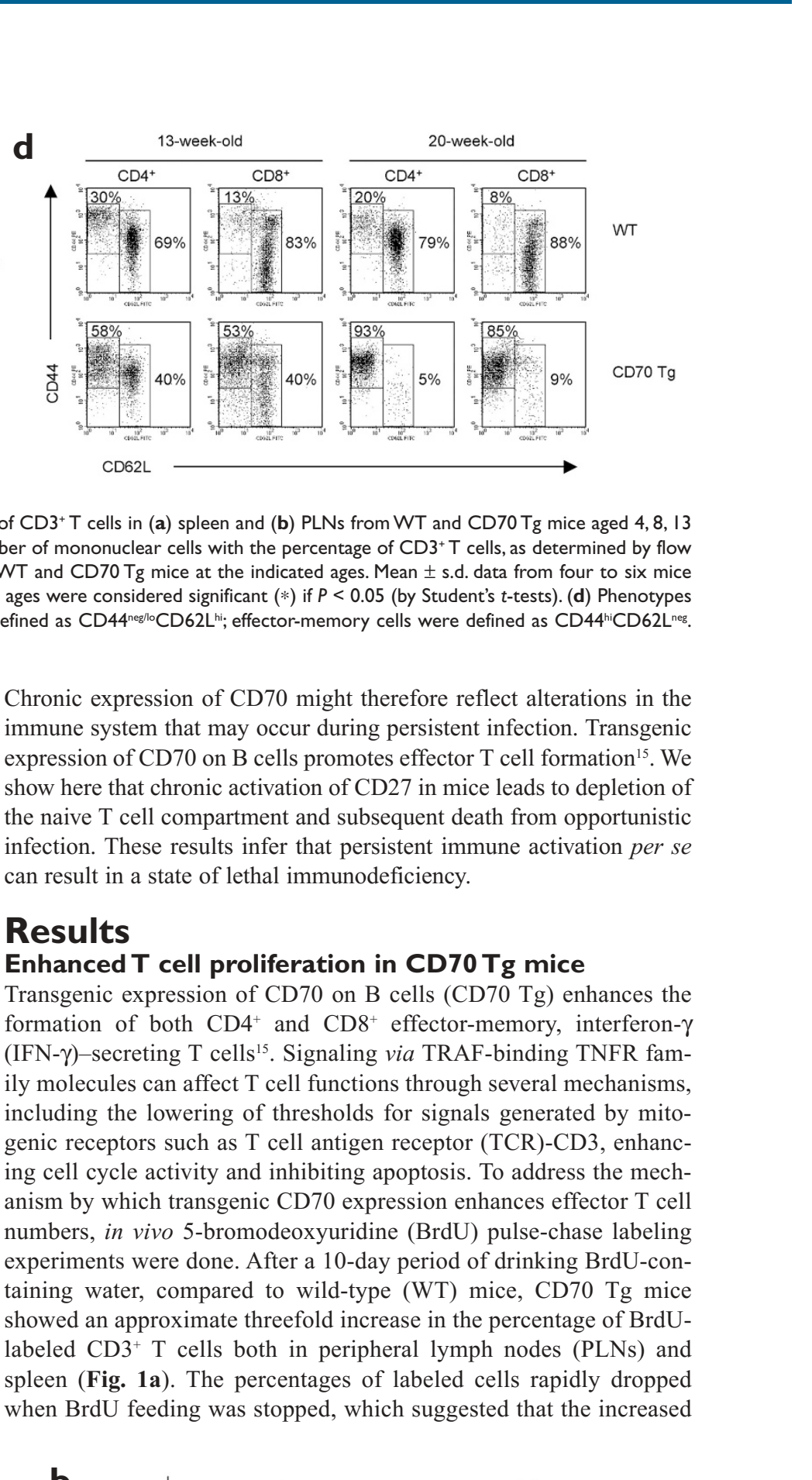

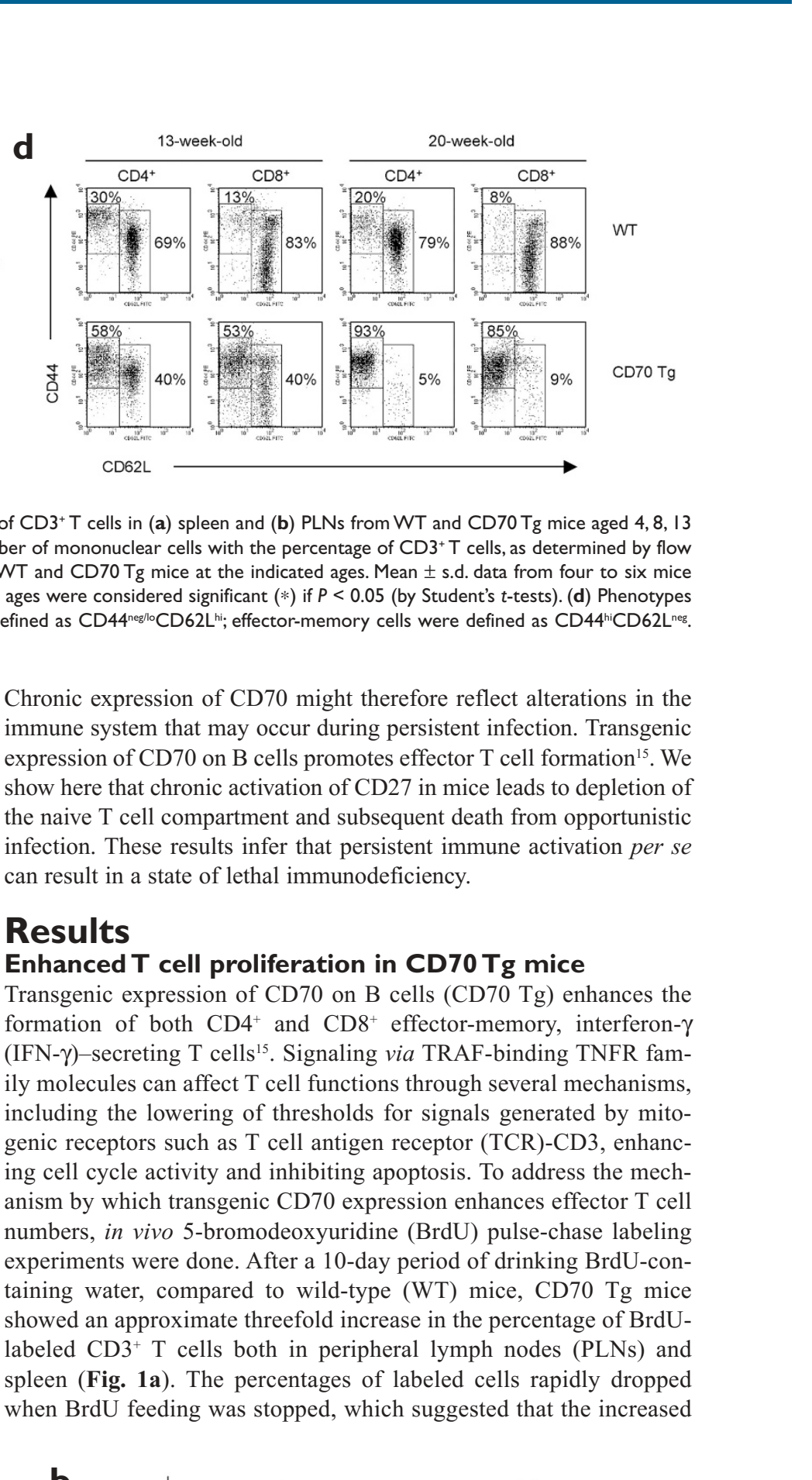

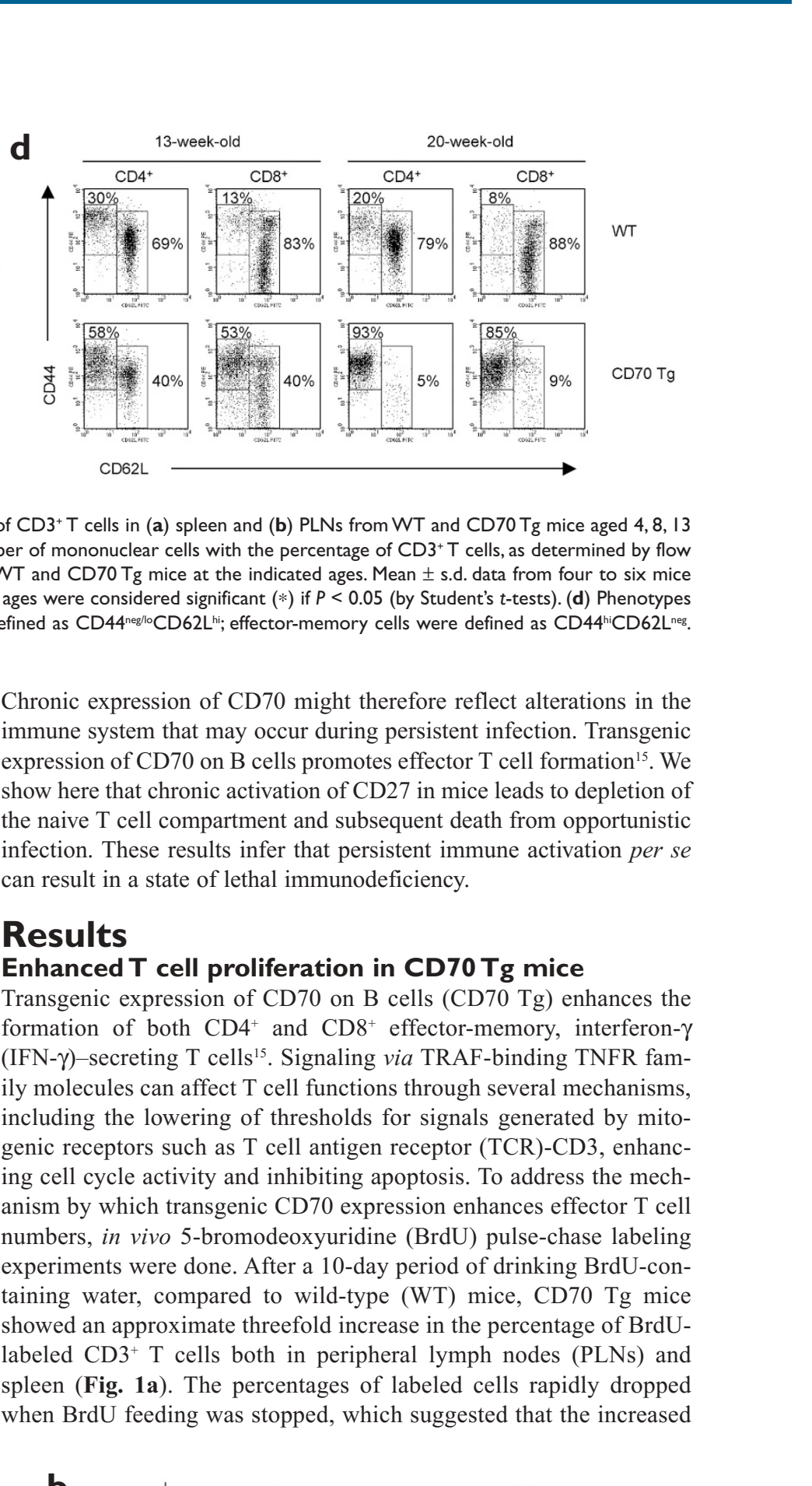

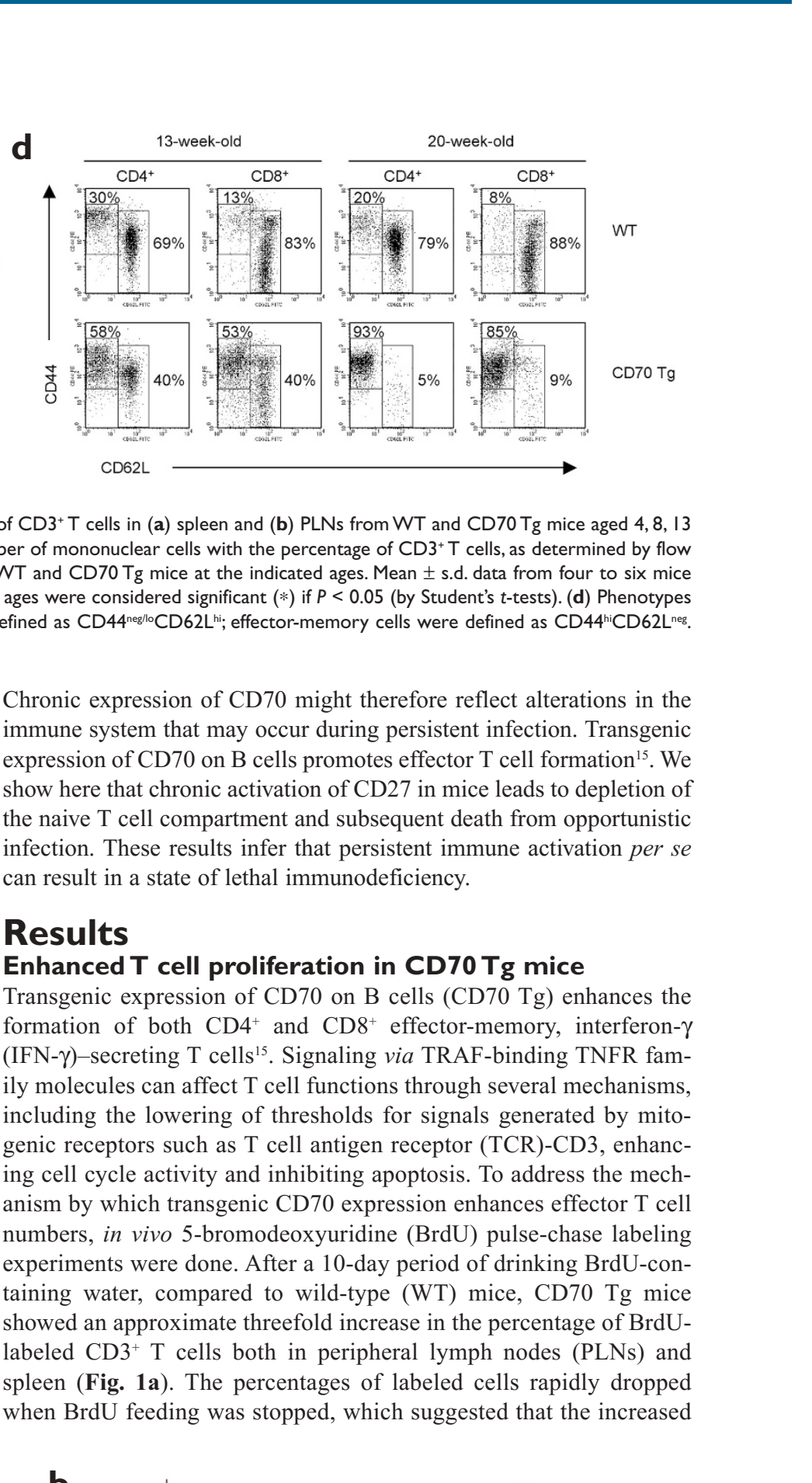

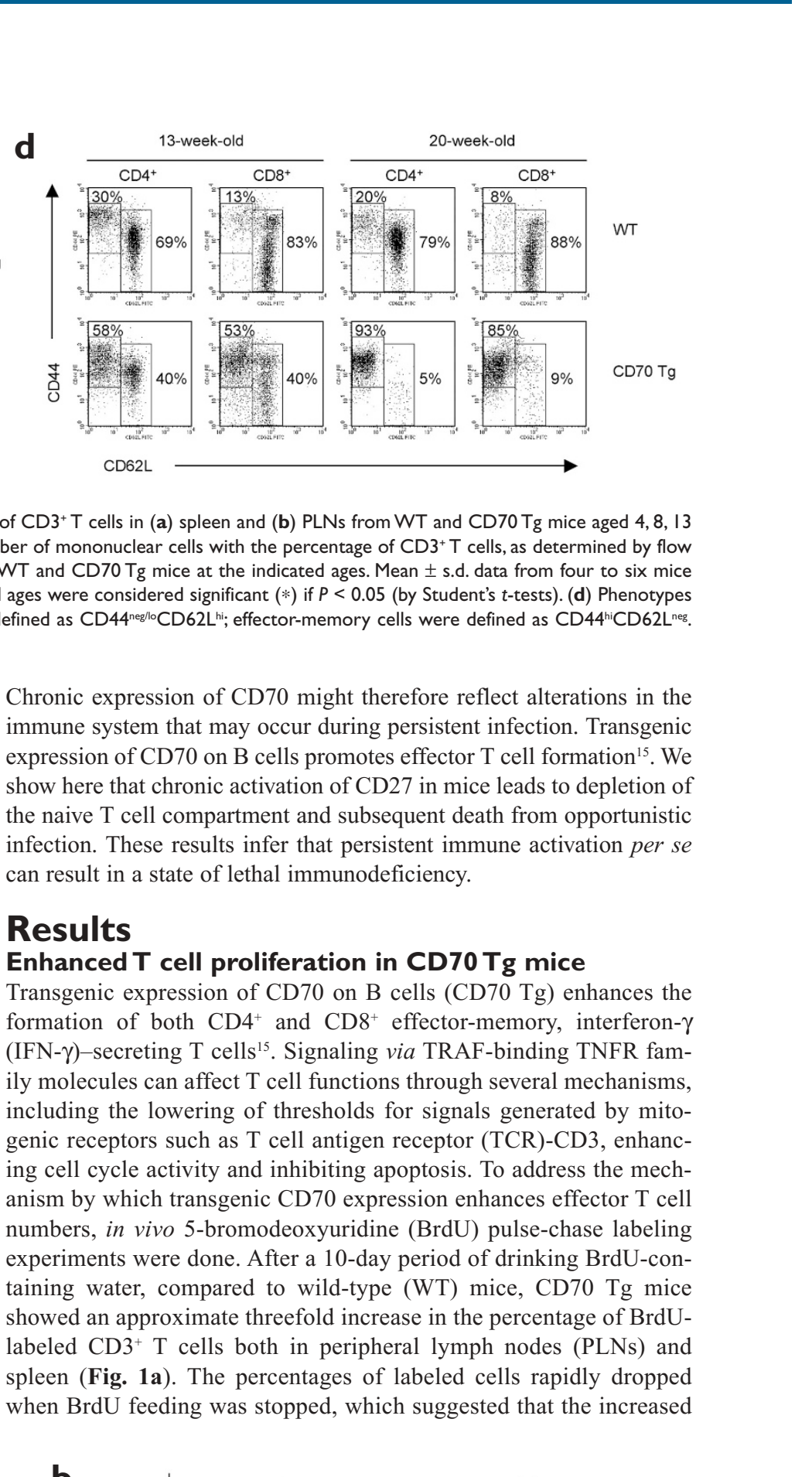

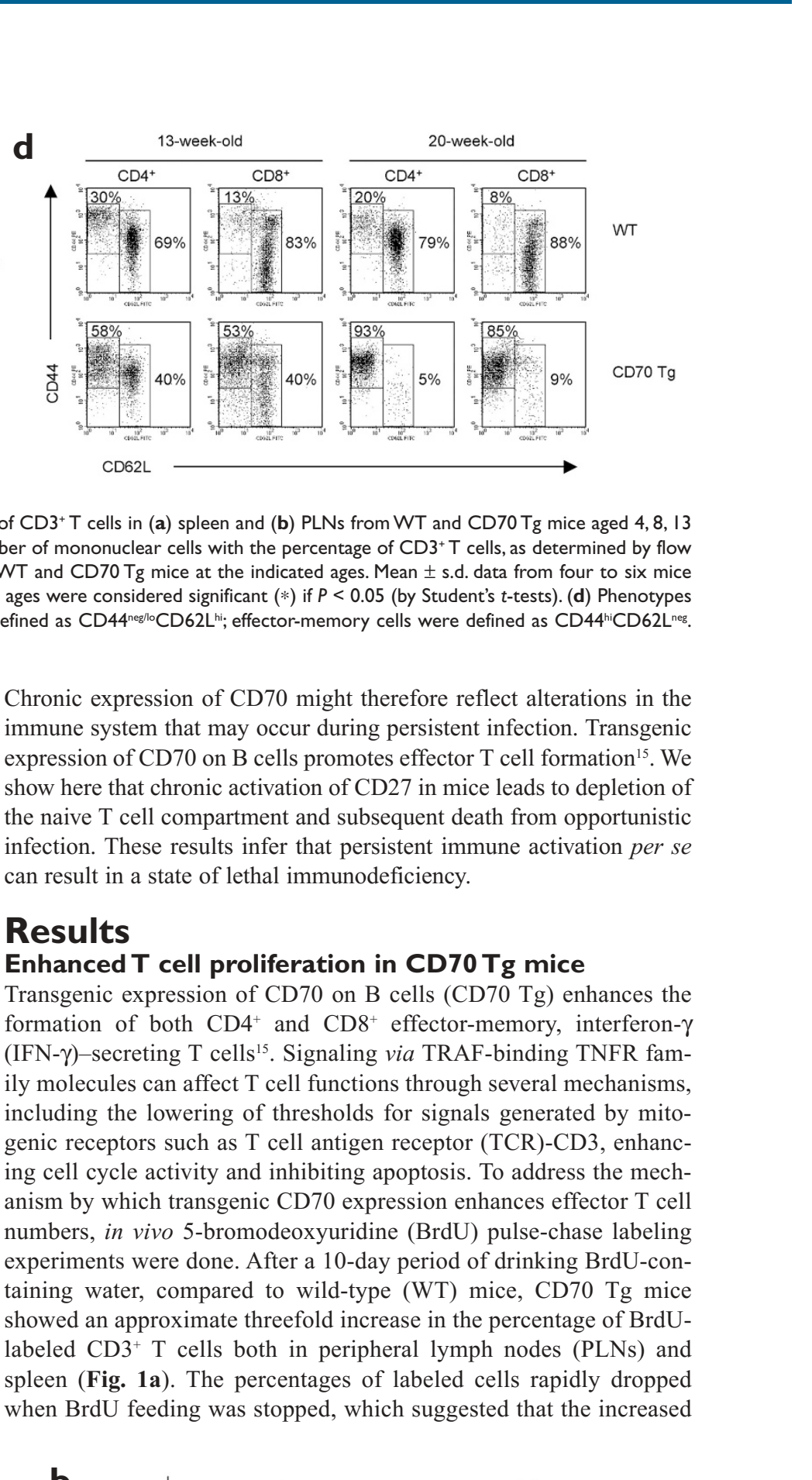

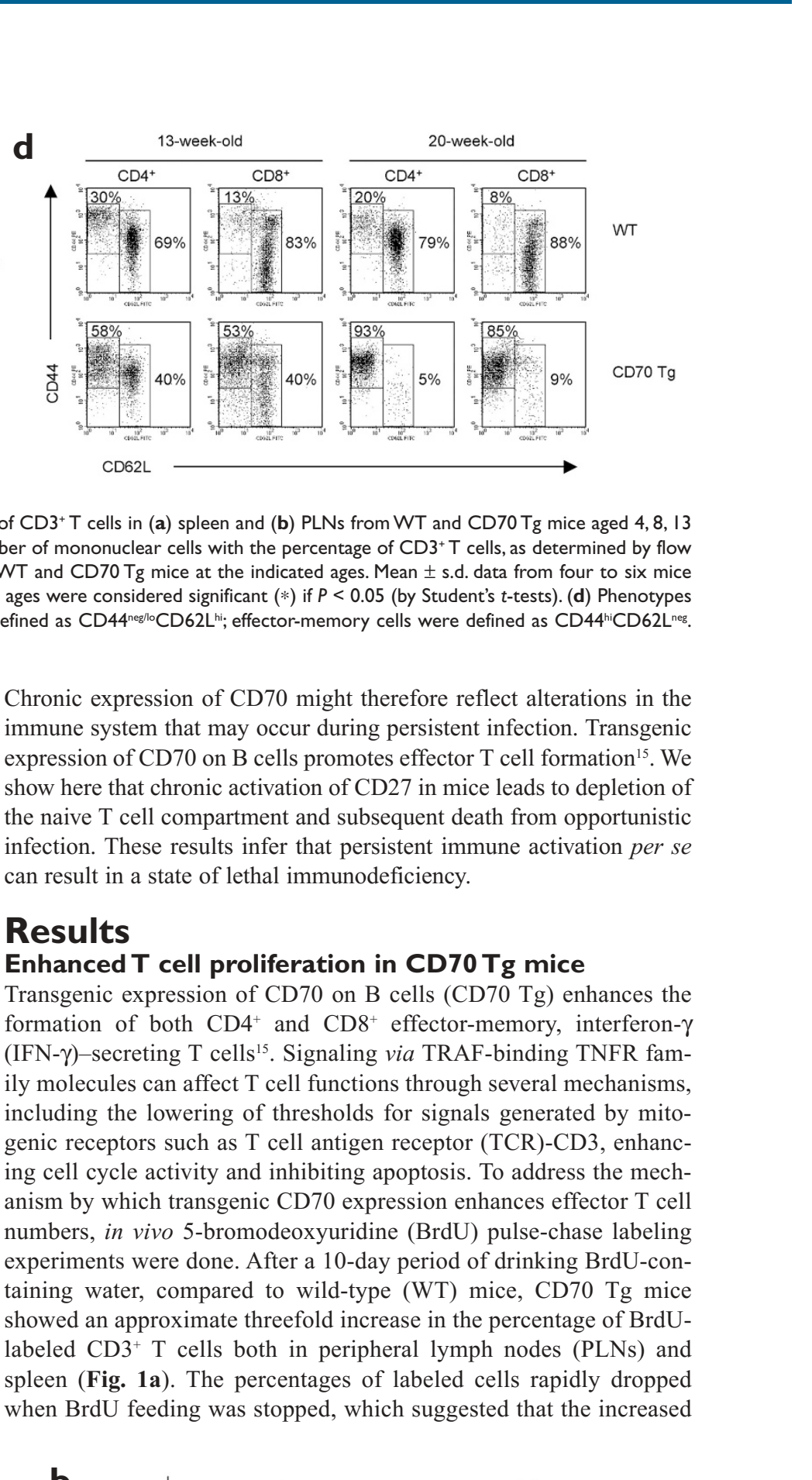

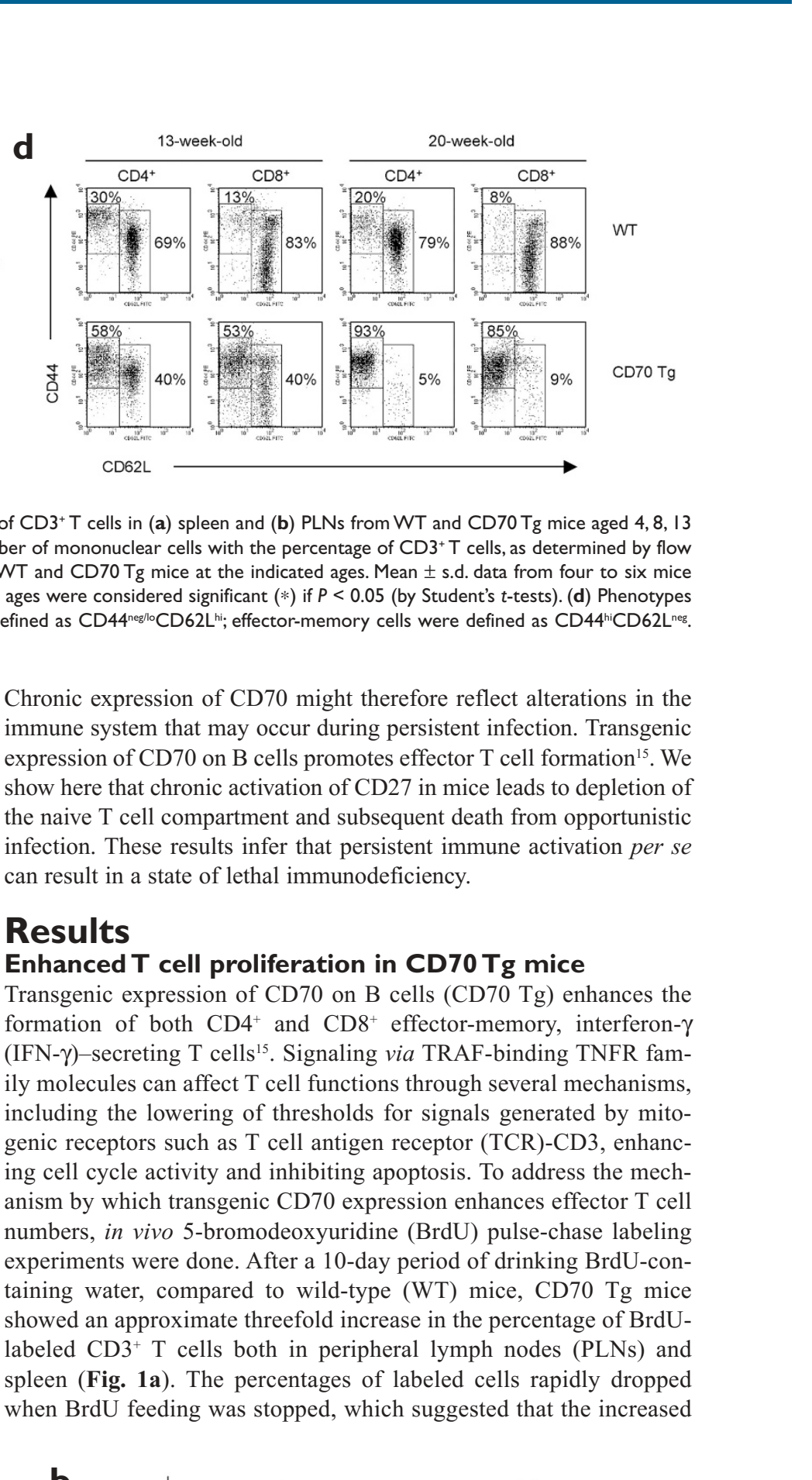

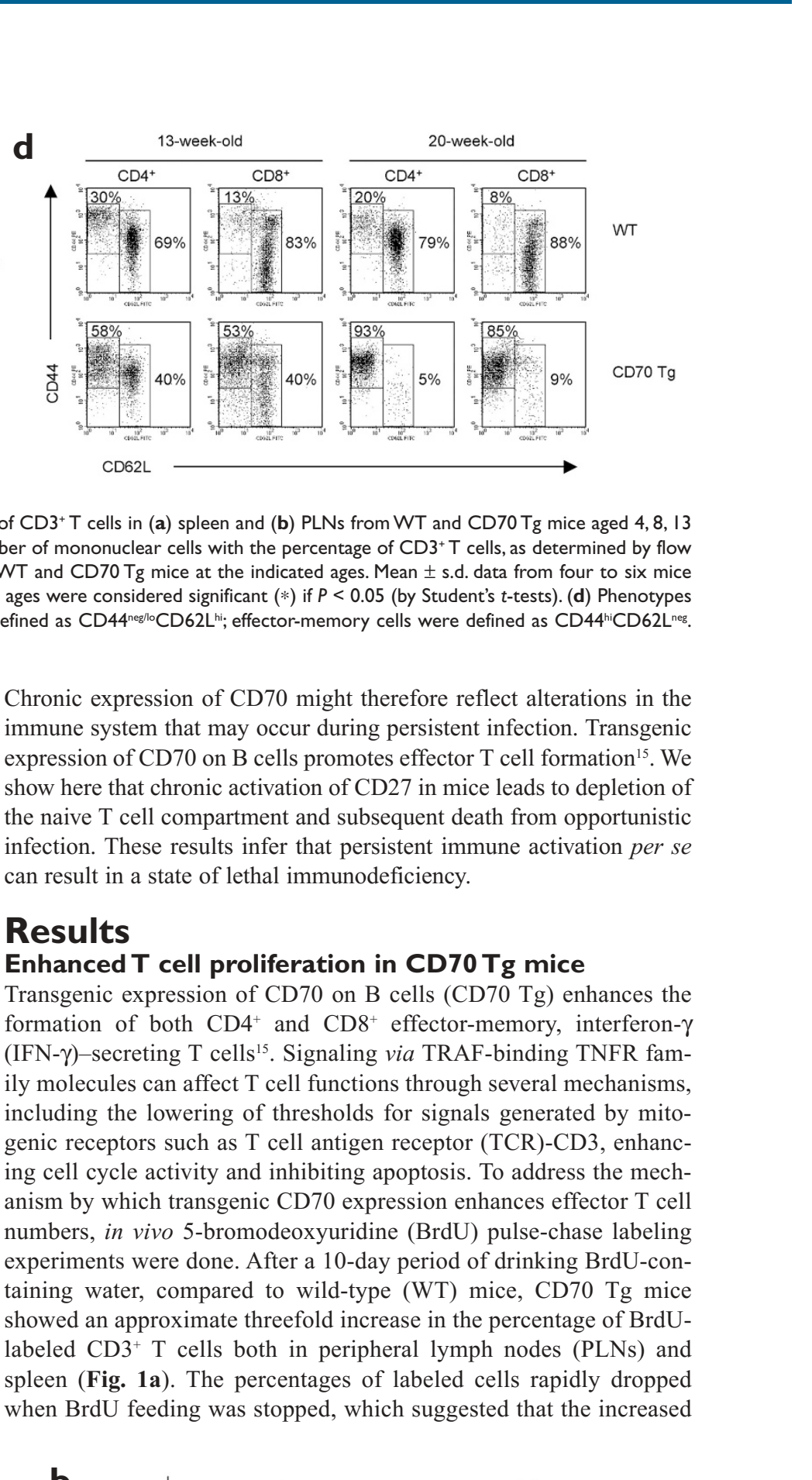

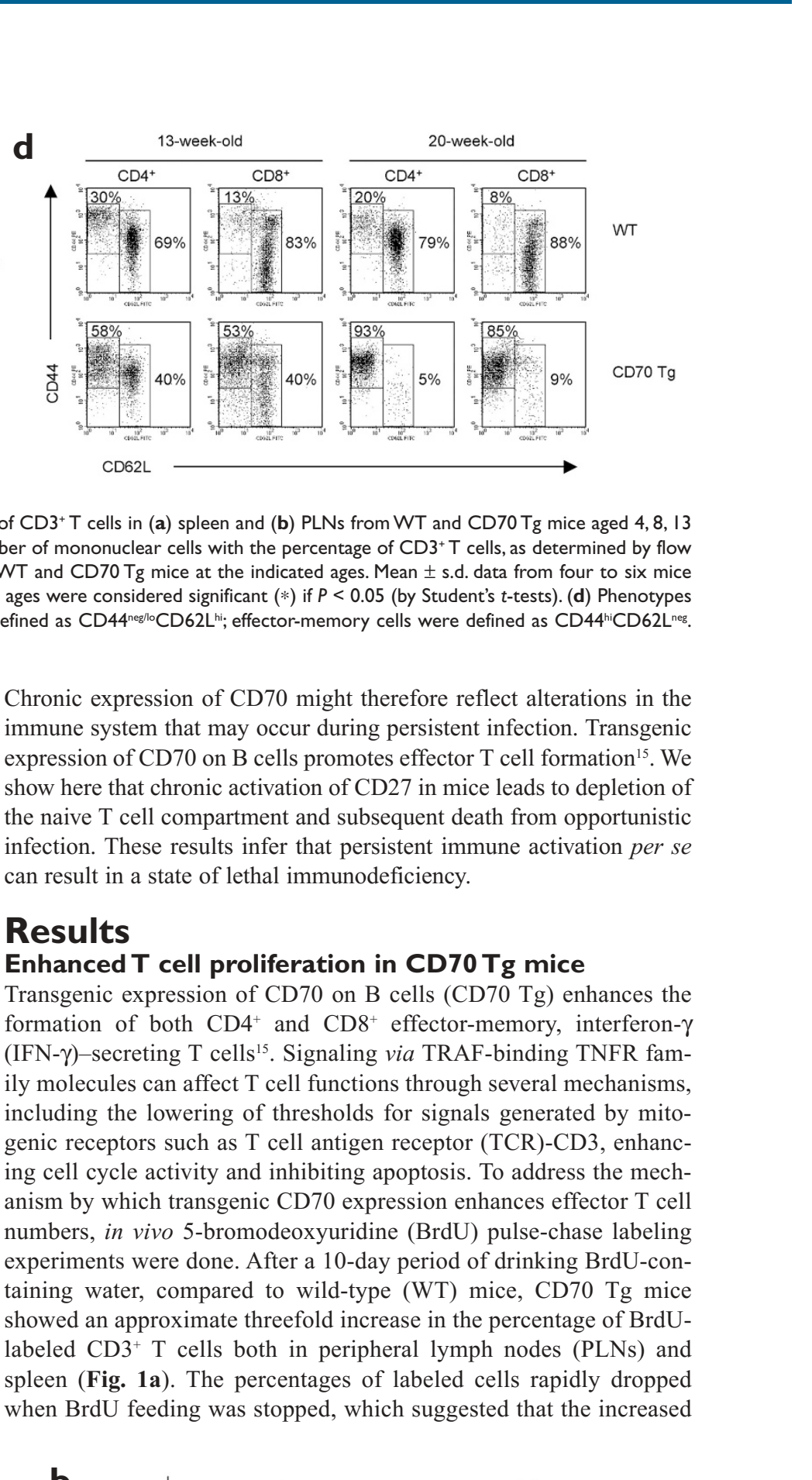

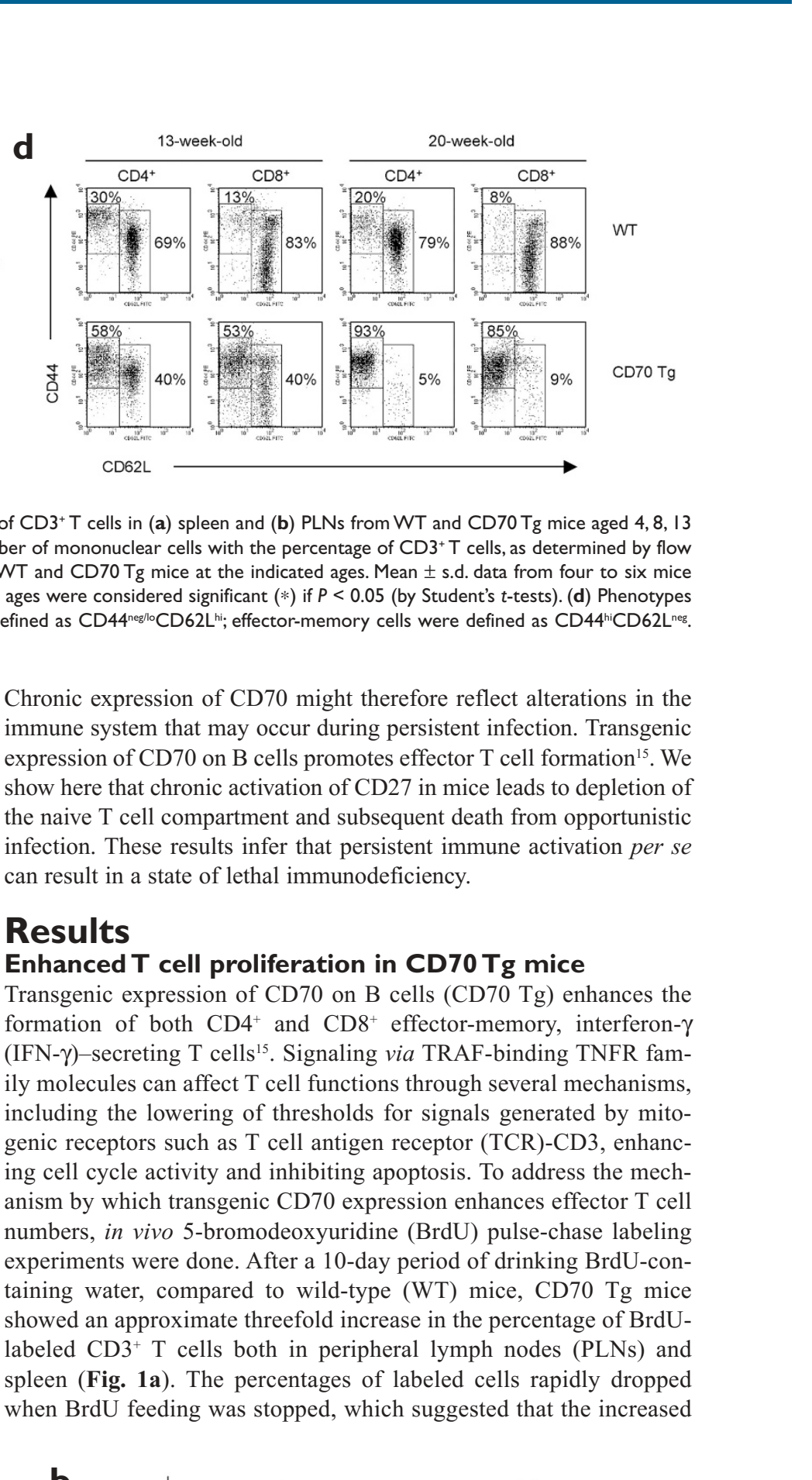

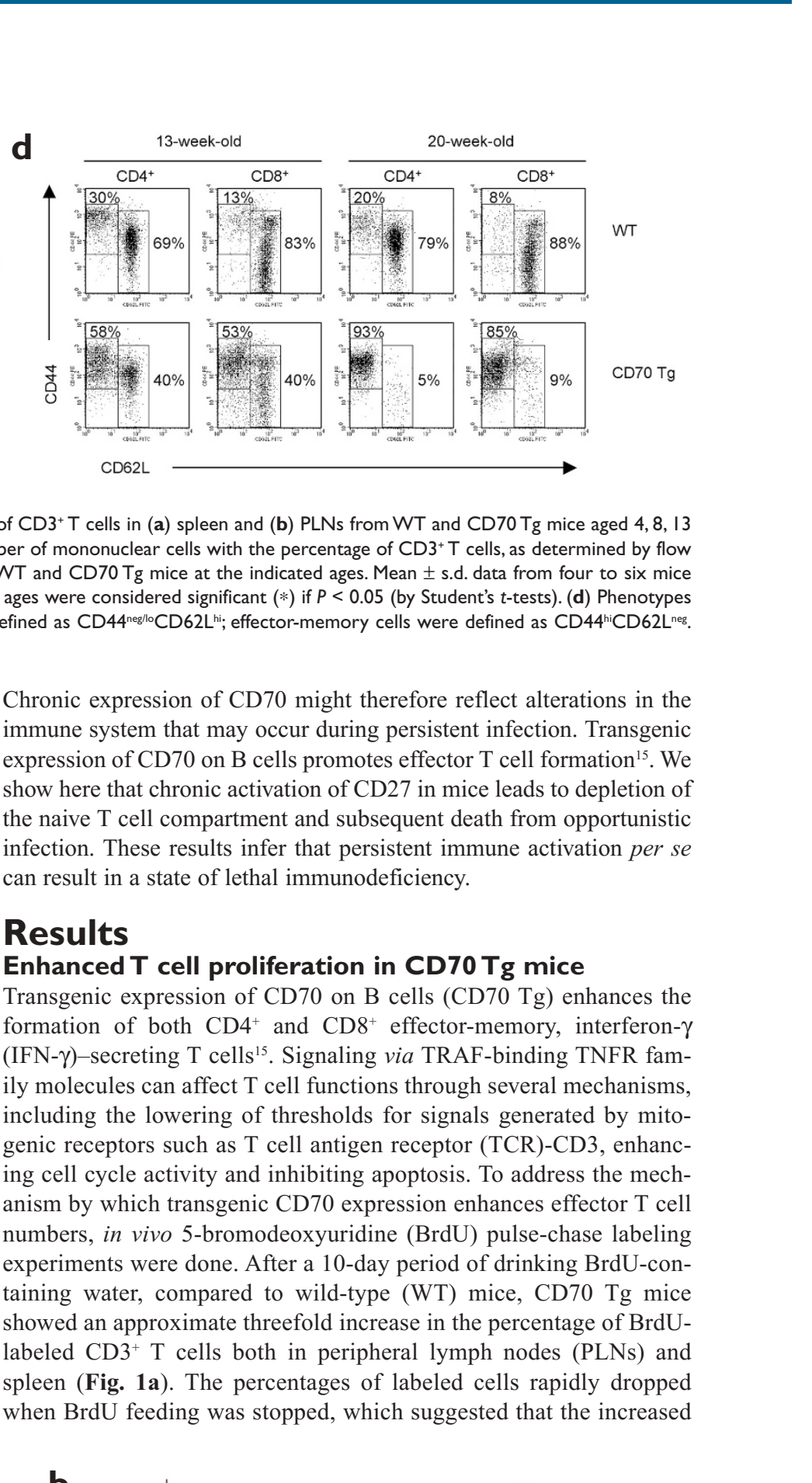

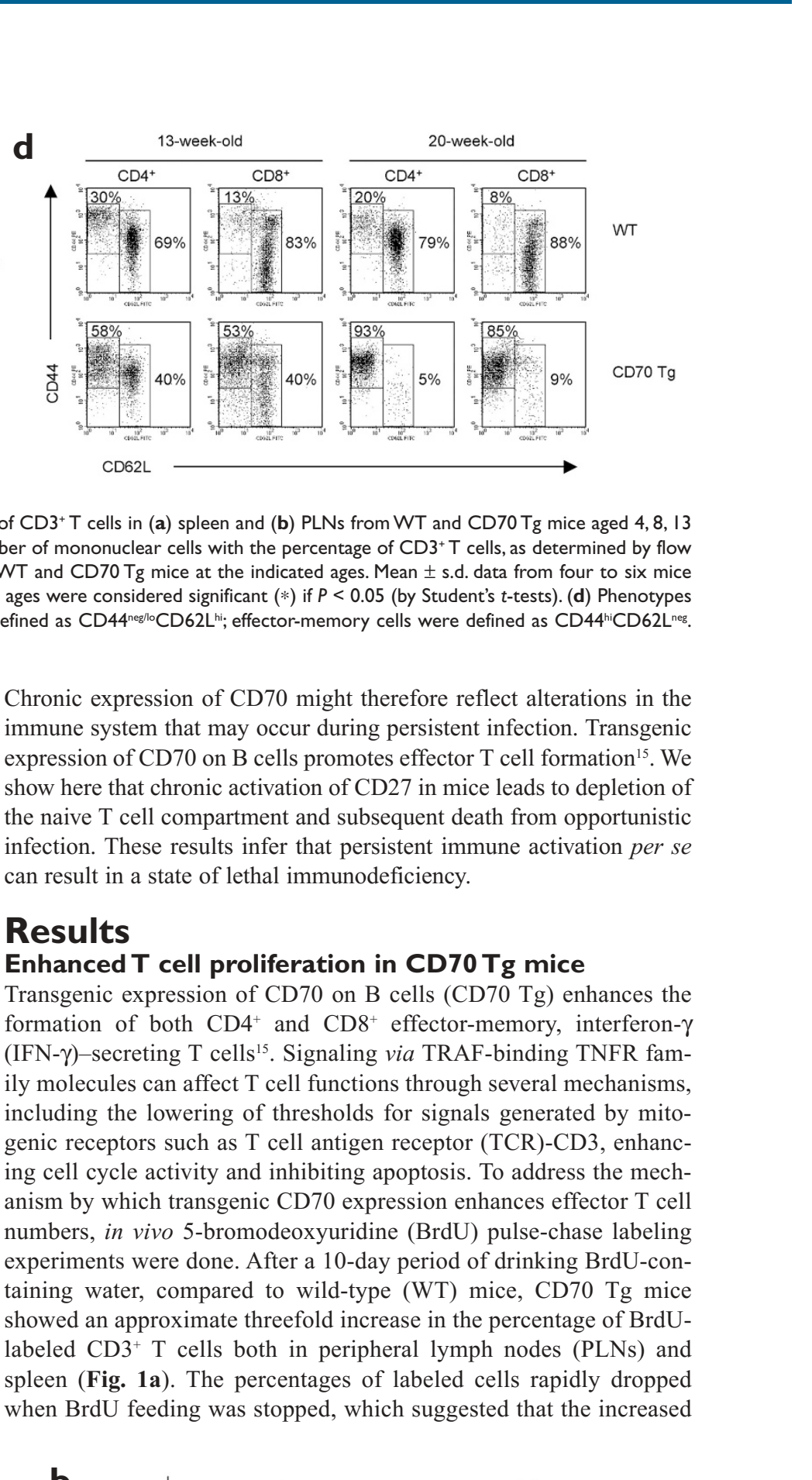

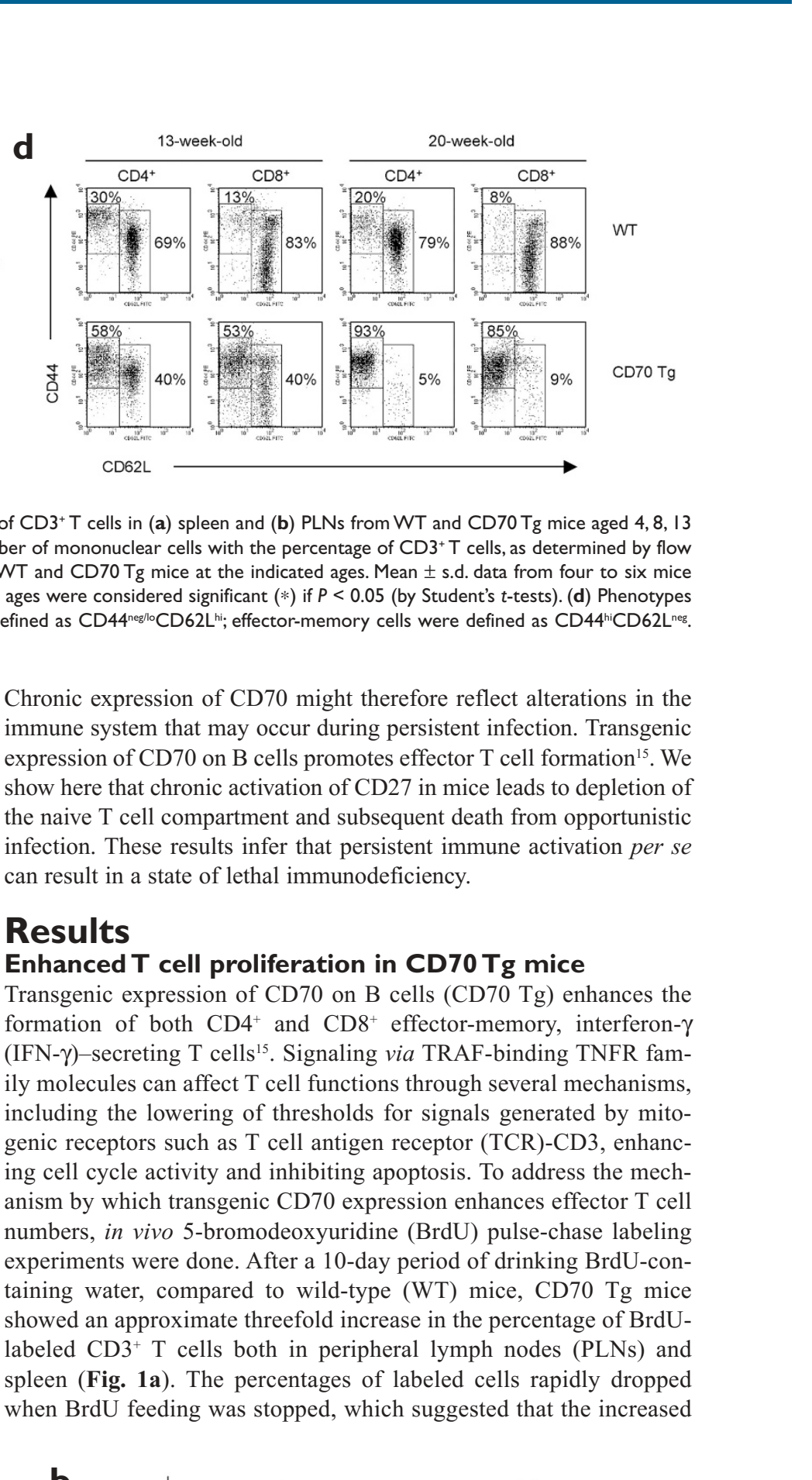

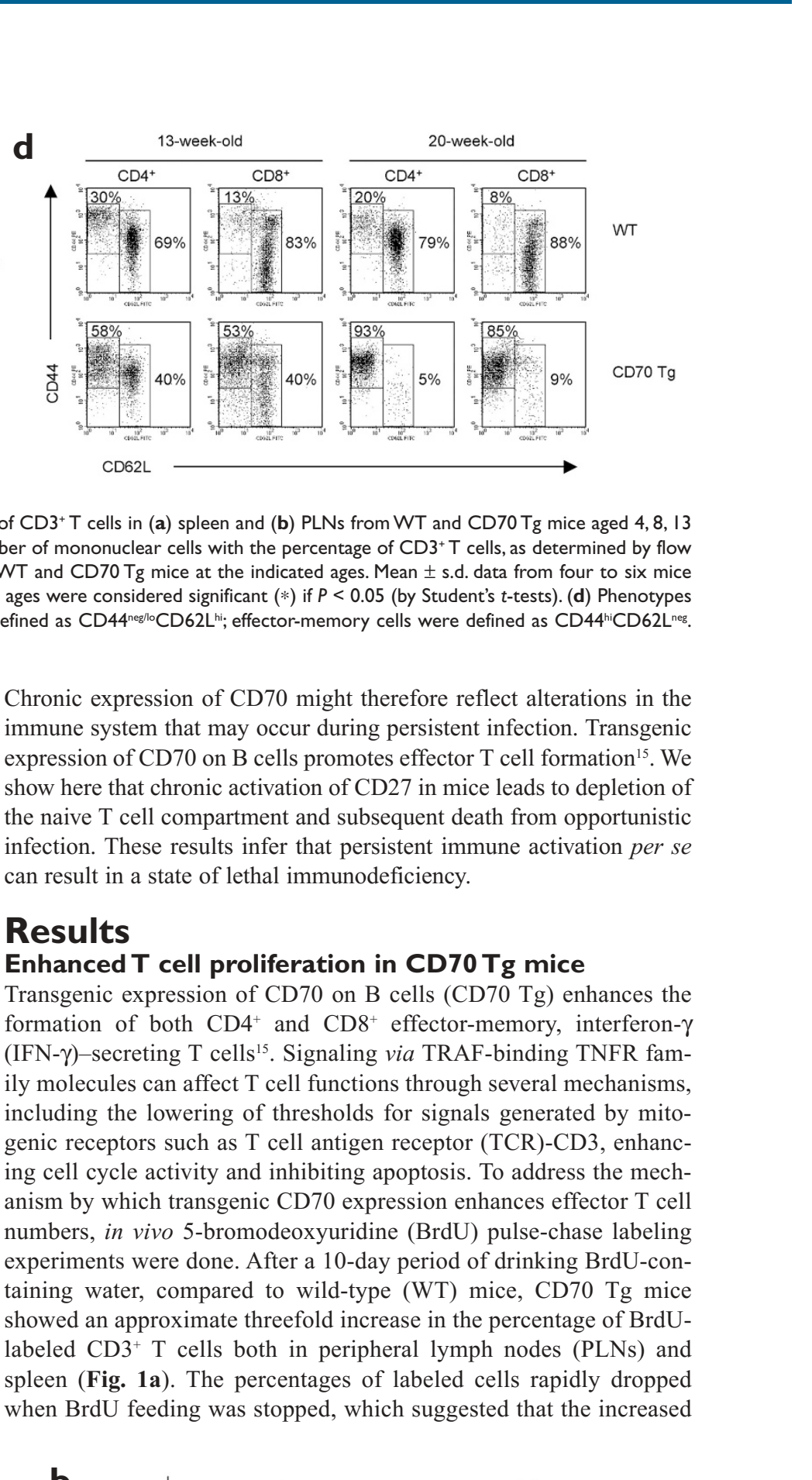

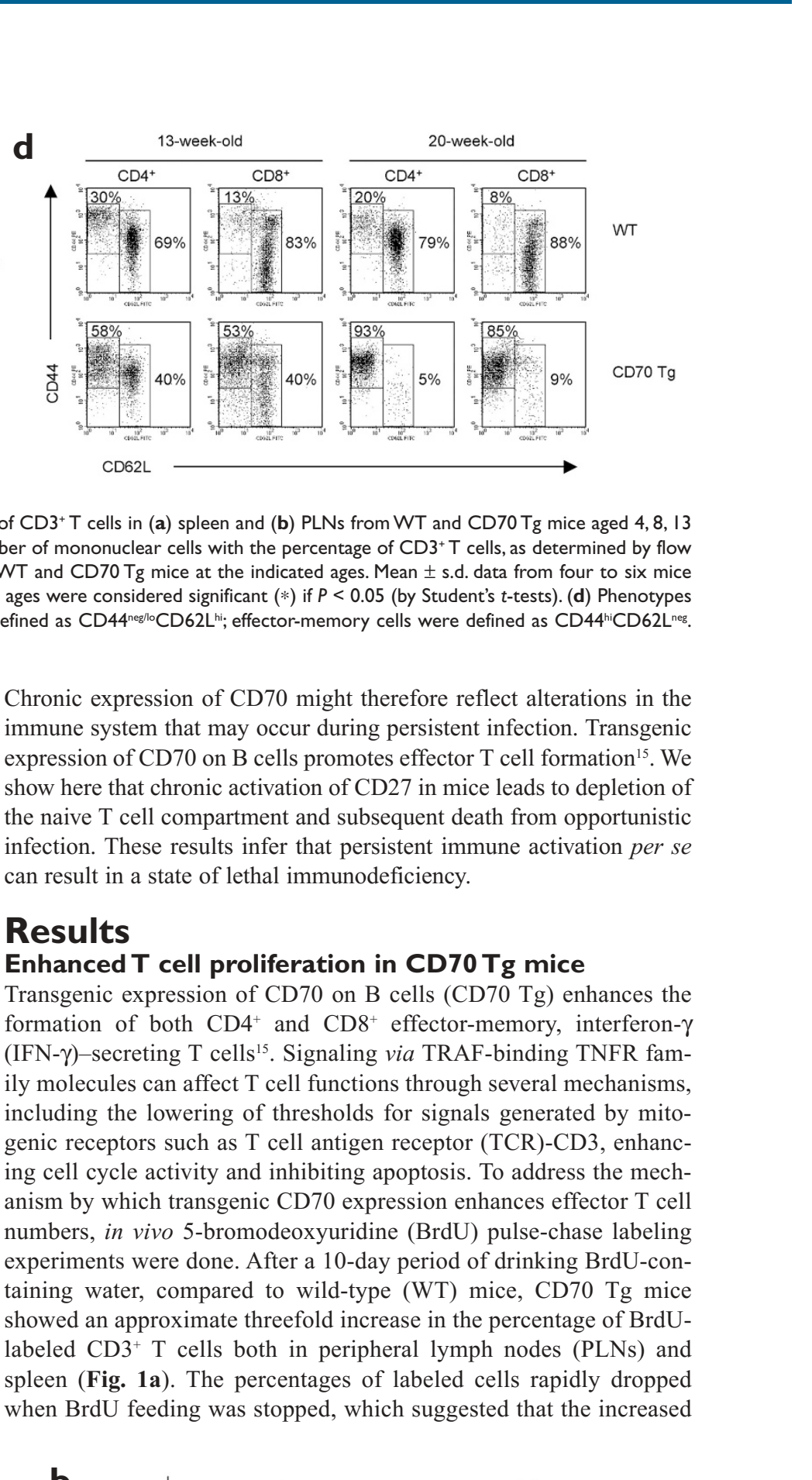

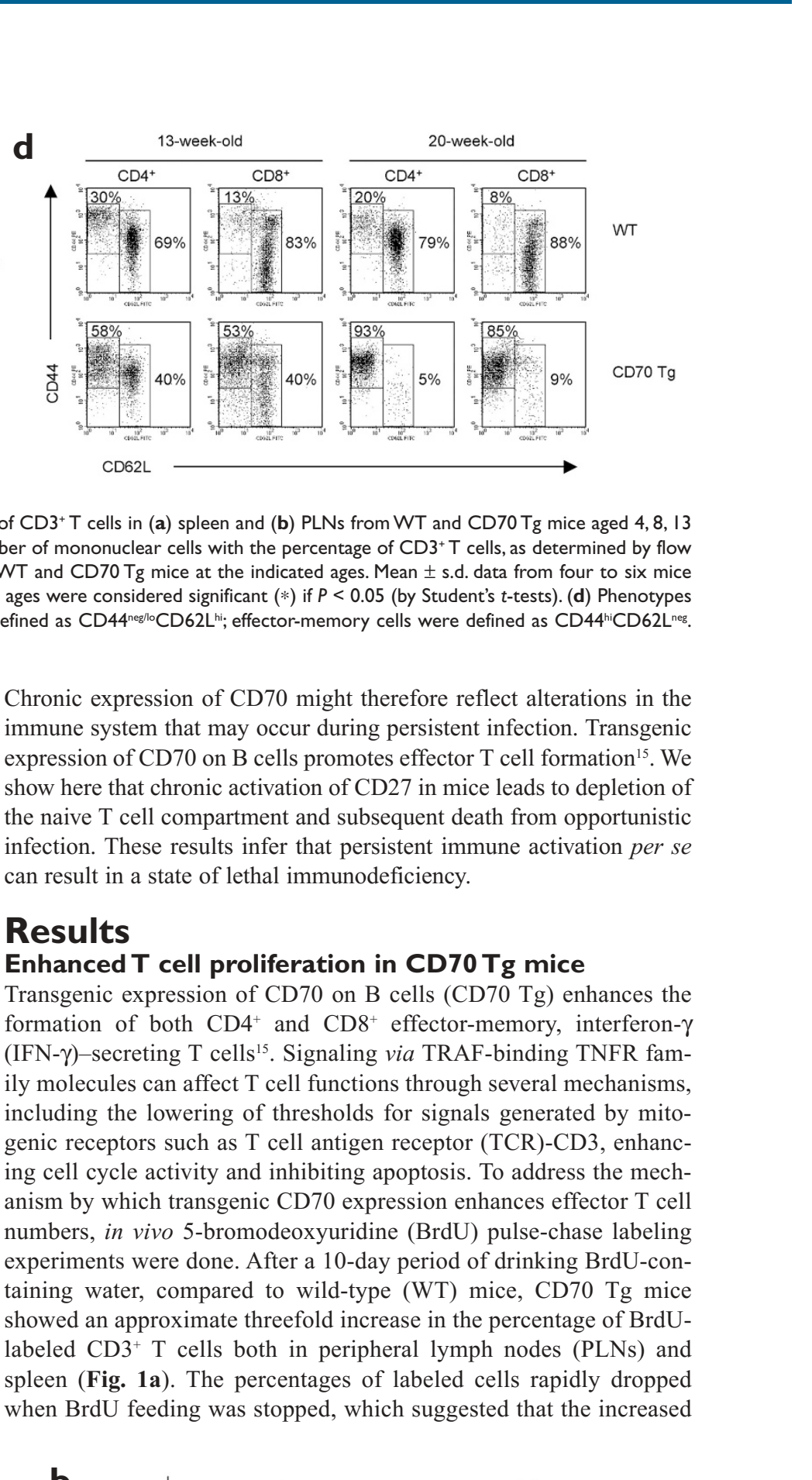

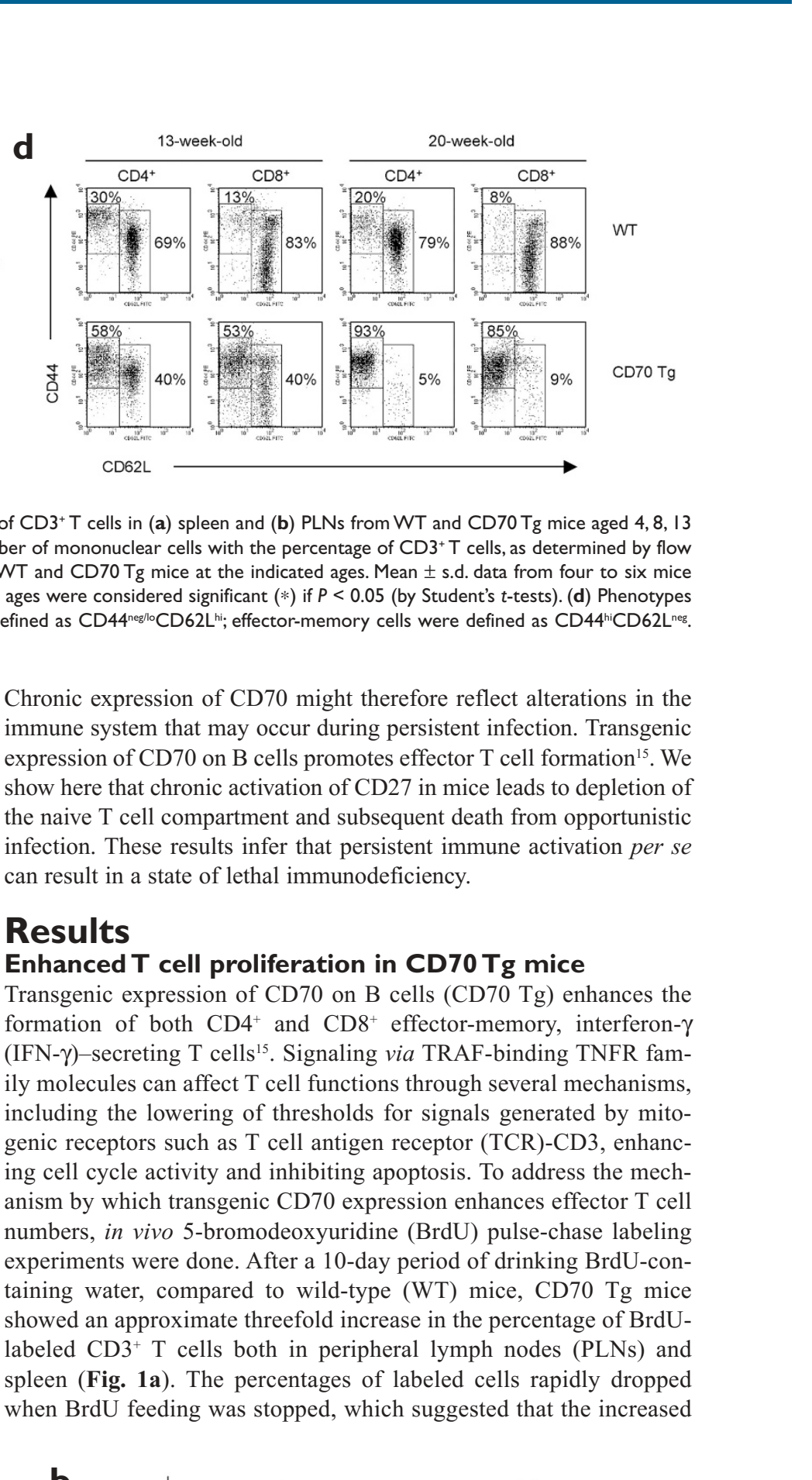

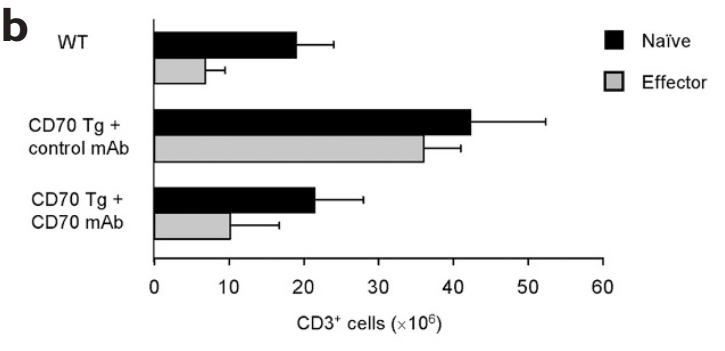

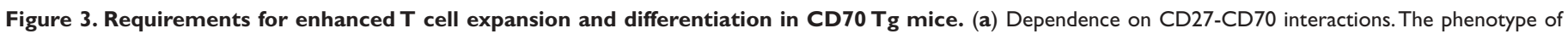

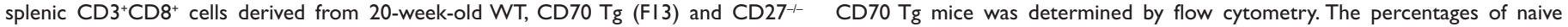

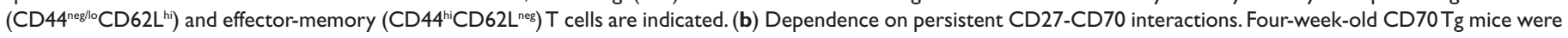

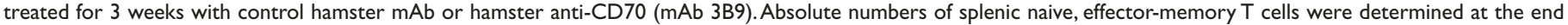

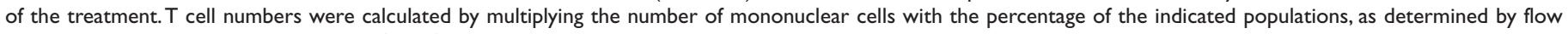
cytometry. Mean \pm s.d. values are shown $(n=3)$. 
a

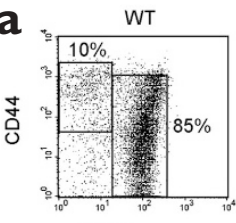

CD62L

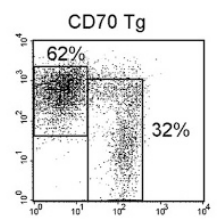

b

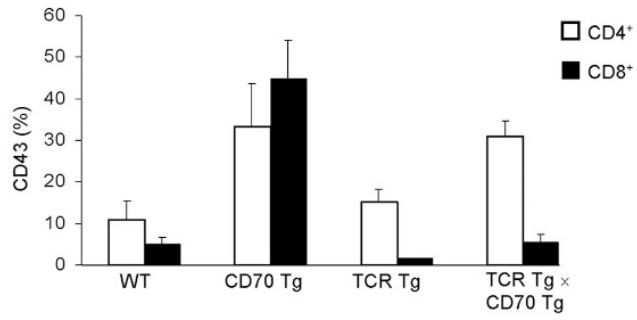

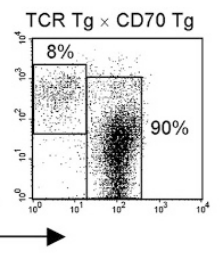
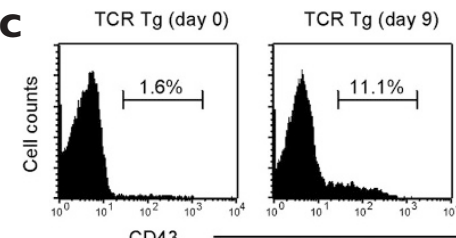

$\operatorname{TCR} \operatorname{Tg} \times$

CD70 Tg (day 9)

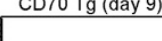

labeling was not due to impaired apoptosis, but rather reflected increased cell division.

To analyze this directly we measured the percentages of cycling and apoptotic cells within the T cell pool of PLNs and spleen. As measured by Ki-67 expression, CD70 Tg mice had increased percentages of $\mathrm{T}$ cells in cycle in PLNs (3.3\% in CD70 Tg versus $1.3 \%$ in WT) and spleen $(14.5 \%$ in CD70 Tg versus $3.3 \%$ in WT) (Fig. 1b). FACS analysis of annexin $\mathrm{V}$ and propidium iodide (PI) staining was done to estimate the percentage of apoptotic cells (annexin $\mathrm{V}^{+} \mathrm{PI}^{-}$or annexin $\mathrm{V}^{+} \mathrm{PI}^{+}$). $\mathrm{T}$ cell death rates appeared to be relatively constant in WT mice and no differences were observed with $\mathrm{CD} 70 \mathrm{Tg}$ mice of 4,8 and 13 weeks of age (data not shown). In 20-week-old CD70 Tg mice, a small increase in the percentage of apoptotic cells was seen in the PLNs (40\% in CD70 Tg versus $27 \%$ in WT, $P<0.05$ ) and the spleen ( $42 \%$ in CD70 Tg versus $23 \%$ in WT, $P<0.05$ ) (data not shown).

The ability of T cells to undergo clonal expansion was measured (Fig. 1c). Irrespective of age, lymph node $\mathrm{T}$ cells from $\mathrm{CD} 70 \mathrm{Tg}$ mice showed a reduced ability to divide upon stimulation with monoclonal antibody $(\mathrm{mAb})$ to $\mathrm{CD} 3$ in vitro: mean $\left[{ }^{3} \mathrm{H}\right]$ thymidine incorporation ranged from $48 \%$ to $68 \%$ compared to WT mice. In contrast, proliferation in response to phytohemagglutinin was normal in 4-week-old mice (mean $\left[{ }^{3} \mathrm{H}\right]$ thymidine incorporation was $180 \%$ compared to WT mice) but dropped as the animals aged (at 20 weeks, mean $\left[{ }^{3} \mathrm{H}\right]$ thymidine incorporation was reduced to $62 \%$ compared to WT mice). Thus, T cells from CD70 Tg mice showed increased proliferation in vivo and had a decreased ability to divide upon polyclonal stimulation in vitro.

\section{Diminution of naive T cells in CD70 Tg mice}

To investigate the long-term effects of enhanced $\mathrm{T}$ cell proliferation in vivo, $\mathrm{T}$ cell numbers in the lymphoid organs of CD70 Tg mice were analyzed longitudinally. T cell numbers in PLNs were increased in transgenic mice of 4 and 8 weeks of age compared to WT mice (Fig 2a). Both $\mathrm{CD}^{+}$and $\mathrm{CD}^{+} \mathrm{T}$ cells contributed to this increase ${ }^{15}$ (data not shown). As mice aged, lymph node T cell numbers dropped sharply. At 20 weeks, PLNs had strongly involuted and T cell numbers in CD70 Tg mice were below $10 \%$ of the amount found in WT mice (Fig. 2a). In contrast to the $\mathrm{T}$ cell numbers in PLNs, splenic $\mathrm{T}$ cell numbers were increased compared to WT mice irrespective of age (Fig 2b). However, the accumulation of effector-memory cells appeared to be progressive and at 20 weeks of age the majority of splenic T cells, both $\mathrm{CD}^{+}$and $\mathrm{CD} 8^{+}$, were of the effector-memory $\mathrm{CD} 44^{\text {hi }} \mathrm{CD}^{2} \mathrm{~L}^{-}$phenotype (Fig. 2d). The combined changes in spleen and PLNs resulted in an almost complete diminution of the naive $\mathrm{T}$ cell population in older CD70 $\mathrm{Tg}$ animals. The CD4:CD8 ratio was not significantly different between CD70 Tg and WT mice, neither in young nor aged mice (data shown).

Thymocyte numbers were similar in CD70 Tg and WT mice until 13 weeks of age; however, at 20 weeks of age only thymic remnants with low cellularity could be recovered from the Tg animals (Fig. 2c). Thymocyte differentiation - as judged by CD4 and CD8 expressionwas unchanged in CD70 Tg mice (data not shown). Thus, constitutive expression of CD70 results in reduced naive $\mathrm{T}$ cell numbers in the secondary lymphoid organs and in diminished production of naive $\mathrm{T}$ cells in aged mice. a

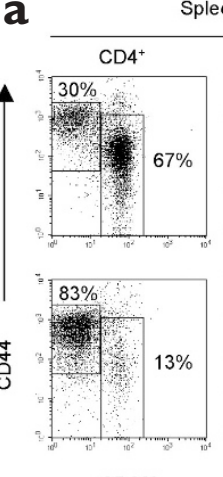

CD62L
Lymph nodes
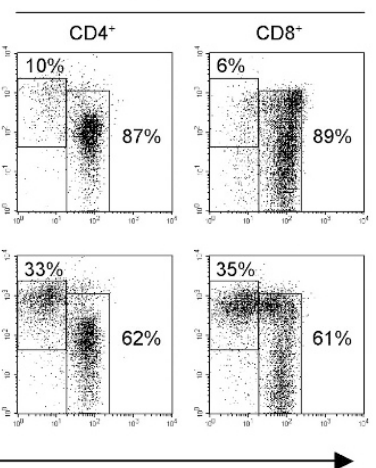

b

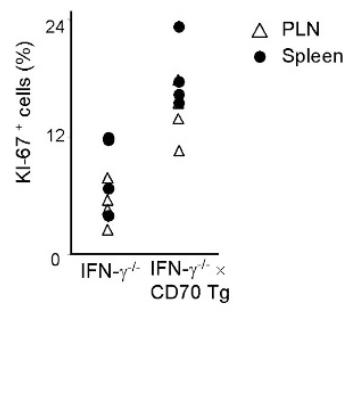

Figure 5.T cell characteristics of IFN $-\gamma^{\prime-} \times$ CD70 Tg mice. (a) Flow cytometric analysis of splenic CD4 ${ }^{+}$ and $\mathrm{CD}^{+}$cells from 20 -week-old WT and CD70 $\mathrm{Tg}$. The percentages of naive and effector-memory $T$ cells are shown. (b) Flow cytometry was done to determine the percentages of $\mathrm{Ki}$ $67^{+}$within the $\mathrm{CD}^{+}$cell populations from spleen and PLNs derived from 20-week-old IFN- $\gamma^{-\alpha}$ and IFN- $\gamma^{-\alpha} \times$ CD70 Tg mice. 
a

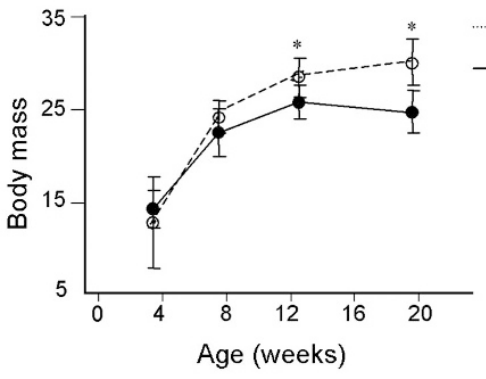

b

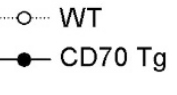

$\rightarrow \mathrm{O} \cdots \mathrm{WT}$
$\rightarrow \mathrm{CD} 70 \mathrm{Tg}$
WT
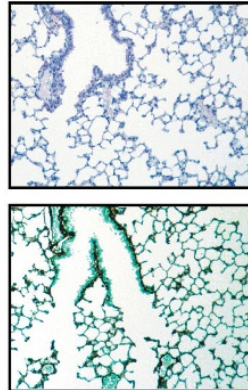

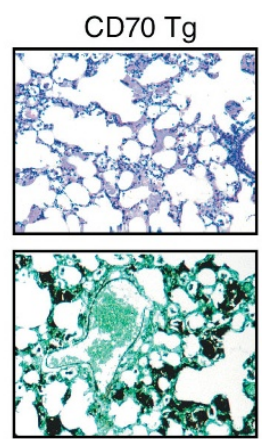

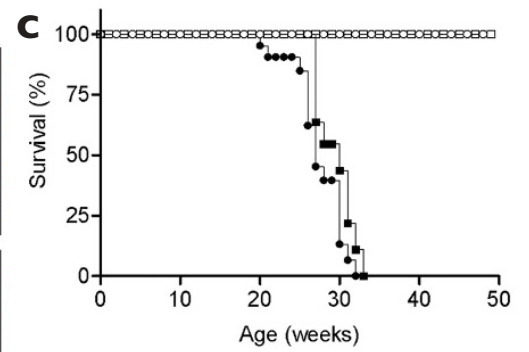

Age (weeks)

$$
\begin{aligned}
& -\mathrm{WTT}(n=24) \\
& -\mathrm{CD} 70 \mathrm{Tg}(n=18) \\
& -\square \mathrm{IFN}-\gamma^{-/-}(n=16) \\
& --\mathrm{IFN}-\gamma^{-/-} \times \operatorname{CD} 70 \mathrm{Tg}(n=8)
\end{aligned}
$$

Figure 6. Clinical symptoms in CD70 Tg mice. (a) Cachexia in CD70 Tg mice. Male WT and CD70 Tg mice were weighed at 4, 8, I3 and 20 weeks of age. Mean \pm s.d. data are shown $(n \geq 6)$. Significant differences (where $P<0.05$ by Student's $t$-tests) between the mean values for WT and CD70 Tg mice are indicated by asterisks $(*)$. (b) Pneumocystis carinii pneumonia in CD70 Tg mice. Hematoxylin-eosin staining (upper panels) and Grocott staining (lower panels) were done on formalin-fixed lung tissue sections derived from WT and CD70 Tg mice. Grocott staining shows cysts of Pneumocystis carinii in sections derived from CD70 Tg mice. Magnification: $\times 62.5$. (c) Shortened lifespan of CD70 Tg mice. Cumulative survival curves for WT, CD70 Tg, IFN- $\gamma^{\prime-}$ and IFN- $\gamma^{-1} \times$ CD70 Tg mice.

\section{Requirements for effector-memory cell formation}

In contrast to a number of other ligands of the TNF superfamily - such as TNF, TRAIL (TNF-related apoptosis inducing ligand) and LIGHTCD70 appears to have only one receptor, CD27. The excessive formation of effector-memory $\mathrm{T}$ cells in CD70 Tg mice was completely abolished when these mice were crossed with CD27 $7^{-/}$animals (Fig. 3a). This finding was in agreement with the observation that $\mathrm{T}$ cell and IFN- $\gamma-$ dependent $\mathrm{B}$ cell depletion in CD70 Tg mice can be rescued on a CD27 $7^{-/}$background ${ }^{15}$. In addition, expansion of effector-memory $\mathrm{T}$ cells was dependent on continuous CD27-CD70 interaction, as treatment of 4-week-old CD70 Tg mice with blocking CD70 mAb reduced the number of effector-memory cells compared to WT numbers (Fig. 3b). These results demonstrated that the mechanism of enhanced effector-memory $\mathrm{T}$ cell formation was not only initiated but was subsequently also maintained by CD27-CD70 interaction.

To test whether the interaction between CD27 and CD70 in the absence of a signal delivered through the TCR sufficed to expand the effector-memory pool, CD70 $\mathrm{Tg}$ mice were crossed with mice with a major histocompatibility complex (MHC) class I-restricted transgenic TCR specific for influenza A virus (TCR Tg), which was not present in the mouse colony. In these double transgenic mice, CD70 expression did not enhance $\mathrm{CD}^{+}$effector-memory $\mathrm{T}$ cell formation. The $\mathrm{CD} 8^{+} \mathrm{T}$ cell compartments of both TCR Tg and TCR Tg $\times$ CD70 Tg mice (which were largely composed of TCR Tg T cells) was composed of naive T cells (Fig. 4a,b). In contrast, the nontransgenic $\mathrm{CD}^{+} \mathrm{T}$ cell compartment in the TCR Tg $\times$ CD70 Tg mice predominantly contained effectormemory $\mathrm{T}$ cells, as shown by expression of the effector $\mathrm{T}$ cell marker CD43 ${ }^{16}$ (Fig. 4b). After intranasal infection with influenza virus, TCR $\mathrm{Tg} \times \mathrm{CD} 70 \mathrm{Tg}$ mice generated effector-memory $\mathrm{T}$ cells much more efficiently than single TCR Tg mice (Fig. 4c), which corroborated that the effects of persistent CD27-CD70 interactions on $\mathrm{T}$ cells require activation of the TCR by antigen. In CD70 Tg mice these signals were likely provided by environmental antigens.

CD70 Tg mice have increased numbers of IFN- $\gamma$-secreting T cells and the in vivo effects of this regulatory cytokine are reflected by enhanced MHC class II expression and inhibitory action on B cell precursor cells ${ }^{15}$. IFN- $\gamma$ may also play a role in selection and maintenance of the effector-memory $\mathrm{T}$ cell pool ${ }^{17}$. Therefore, to test whether IFN- $\gamma$ has a regulatory role on effector-memory $\mathrm{T}$ cell formation in the CD70
$\mathrm{Tg}$ mice, we analyzed subset distribution and $\mathrm{T}$ cell cycling in vivo of 20 -week-old IFN- $\gamma^{-1} \times$ CD70 Tg mice. In these mice, we also observed a skewing towards effector-memory $\mathrm{T}$ cells (Fig. 5a) and an increase in the percentage of cycling cells, as shown by Ki-67 staining (Fig. 5b); these observations were similar to our findings in IFN- $\gamma$-proficient CD70 Tg animals (Fig 1b). Thus, excessive formation of effector-memory cells in CD70 Tg mice was dependent on CD27-CD70 interactions and foreign antigens, but independent of IFN- $\gamma$.

\section{Premature death of CD70 Tg mice}

During the first months of life CD70 Tg mice appeared healthy, showed enhanced delayed-type hypersensitivity reactions and mounted normal primary antibody responses to protein antigens (unpublished data). However, as CD70 $\mathrm{Tg}$ mice aged they failed to thrive so that at 20 weeks they had a body mass of $\sim 80 \%$ of that of WT animals (Fig. 6a). Most 20-week-old CD70 Tg mice suffered from Pneumocystis carinii pneumonia (Fig. 6b), an opportunistic infection usually seen in situations of severe $\mathrm{T}$ cell immunodeficiency ${ }^{7}$; this was accompanied by a premature death at an average age of 28 weeks (Fig. 6c). This inability to cope with opportunistic pathogens appeared to be a direct result of the enhanced effector-memory cell formation and the concurrent collapse of the naive T cell compartment because Pneumocystis carinii pneumonia was not observed in $\mathrm{CD} 27^{-/} \times \mathrm{CD} 70 \mathrm{Tg}$ nor in TCR $\mathrm{Tg} \times$ CD70 Tg mice (data not shown). IFN $-\gamma^{-1} \times$ CD70 $\mathrm{Tg}$ animals also had infections, which resulted in premature death at an average age of 30 weeks (Fig. 6c). Thus, premature death in CD70 Tg mice appeared to be directly related to the demise of the naive $\mathrm{T}$ cell compartment and was caused by opportunistic infections.

\section{Discussion}

Here we showed that chronic stimulation of murine T cells via CD70 induced excessive effector-memory $\mathrm{T}$ cell formation in a CD27- and antigen-dependent, but IFN- $\gamma$-independent, manner. At the same time, the naive $\mathrm{T}$ cell population was progressively depleted from the lymph nodes, which undermined the integrity of the immune system and ultimately led to host death through opportunistic infection. At least two complementary mechanisms may account for the selective depletion of $\mathrm{T}$ cells from the lymph nodes but not spleen. First, T cell activation initiates a differentiation process in which migratory properties change. 
Effector-memory T cells lose CCR7, a chemokine receptor that directs homing towards secondary lymphoid organs. CCR $7^{-1-} \mathrm{T}$ cells have a severely impeded potential to localize in lymph nodes, whereas migration towards the spleen is intact ${ }^{18}$. As most $\mathrm{T}$ cells in CD70 $\mathrm{Tg}$ mice have an effector-memory phenotype $\left(\mathrm{CD} 44^{\mathrm{hi}} \mathrm{CD} 62 \mathrm{~L}^{-}\right)$, it is likely that these cells home to the spleen and other parts of the body but are excluded from lymph nodes. Second, we found that as CD70 Tg mice aged, thymic cellularity sharply dropped. Thymic involution appeared to be related to the enhanced antigen-driven effector-memory cell formation because thymocyte numbers were normal in TCR Tg $\times$ CD70 Tg mice (numbers in TCR Tg $\times$ CD70 Tg mice ranged from $49 \times 10^{6}$ to $72 \times 10^{6}$, compared to $3.9 \times 10^{6}$ to $9.1 \times 10^{6}$ in CD70 Tg mice). Probably, exhaustion of the naive $\mathrm{T}$ cell source reduced seeding of these cells to the secondary lymphoid organs and contributed to the involution of the PLNs.

The reason for the thymus dysfunction in the CD70 Tg mice is unclear. A direct effect of CD70 on maturation of developing thymocytes is unlikely because only occasional transgenic $\mathrm{CD}^{+} 0^{+} \mathrm{B}$ cells could be found in the thymus (data not shown). Also there was no evidence of functional CD27-CD70 interactions in the thymus because CD27 expression on thymocytes, which is down-modulated after CD70 binding, is normal ${ }^{15}$. At the time of thymus involution, B cells had virtually disappeared from the secondary lymphoid organs. As this disappearance resulted from inhibition of $\mathrm{B}$ cell development in the bone marrow, we considered it unlikely that residual mature B cells would preferentially be localized in the thymus. On the other hand we considered the possibility that - in analogy to what has been described in other circumstances - chronic immune activation induced a stress response that, through the action of corticosteroids, impeded thymic output ${ }^{19}$.

Effects of TRAF-binding TNFR family members on lymphocyte function are diverse and include increased expansion, acquisition of effector functions and up-regulation of chemokine receptors. Several mechanisms may contribute to the observed expansion of effectormemory T cells in CD70 Tg mice. TNFR-type molecules may act as costimulatory receptors that convert suboptimal signals delivered through TCR-CD3 to mitogenic ones ${ }^{20,21}$. Up-regulation of anti-apoptotic molecules such as Bcl- $\mathrm{x}_{\mathrm{L}}$ and Bcl-2 is induced by OX40 stimulation and enhanced expression of these molecules increases the pool of antigen-primed $\mathrm{T}$ cells ${ }^{22}$. TNFR family members, such as 4-1BB, may also increase $\mathrm{T}$ cell proliferation ${ }^{23}$. It seems clear that these mechanisms are not mutually exclusive and, in addition, may depend on the strength, duration and context of the specific signal given. In CD27 animals a decreased antigen-specific $\mathrm{T}$ cell pool was found after influenza virus challenge ${ }^{8}$. Costimulation of purified murine T cells in vitro via $\mathrm{CD} 27$ is independent of $\mathrm{T}$ cell division and suggests that $\mathrm{CD} 27$ regulates cell survival ${ }^{8}$. On the other hand, experiments in CD70 $\mathrm{Tg}$ mice provided evidence of enhanced cell cycle activity, which was in line with the observation that CD70 transfectants induce strong CFSE dilution in CD3 mAb-stimulated naive human $\mathrm{T}$ cells (unpublished data). Thus, CD27 signaling may enhance the size of the antigen-stimulated $\mathrm{T}$ cell compartment by several mechanisms.

Because antigenic triggering of lymphocytes determines CD70 expression, CD27-CD70 interaction directly couples the size and function of the antigen-primed population to the amount of antigen. Under physiological conditions, this will lead to an appropriate pool size that will contract when the antigen-bearing pathogen is neutralized or eliminated. However, as suggested by our observations observed in CD70 $\mathrm{Tg}$ mice, this feedback loop of effector cell formation may be harmful to the host in situations of chronic immune activation. In CD70 Tg mice a conspicuous number of phenomena are found that are considered hallmarks of HIV-1-induced immunodeficiency: evidence for increased T cell turnover ${ }^{24}$; initial lymphadenopathy followed by depletion of lymph nodes ${ }^{25}$; diminution of the naive $\mathrm{CD} 4^{+}$and naive $\mathrm{CD} 8^{+}$ $\mathrm{T}$ cell populations ${ }^{26}$; and a progressive inability of $\mathrm{T}$ cells to respond $e x$ vivo to antigen and mitogenic stimuli ${ }^{27}$.

For a long time it was thought that $\operatorname{direct}^{28}$ or indirect ${ }^{29}$ cytopathic effects of HIV-1 accounted for the abundant immune abnormalities in HIV-1. However, it has since been suggested that chronic immune activation, resulting from the inability of the immune system to control HIV-1 replication, might contribute substantially to, and could be the main determinant in, the erosion of the immune system in HIV-1infected individuals ${ }^{30,31}$. Our studies with CD70 Tg mice show that persistent immune activation per se can result in a state of lethal immunodeficiency. Neutralizing CD70 mAb can reverse most features of immune activation, which demonstrates the dependence of the hyperimmune status on persistent CD27-CD70 interaction. Activated $\mathrm{T}$ cells from HIV-1-infected individuals also have enhanced CD70 expression $^{32}$ and HIV-infected individuals have increased percentages of $\mathrm{CD} 4{ }^{+} \mathrm{CD} 27^{-} \mathrm{T}$ cells ${ }^{33}$, which could hint at augmented CD27-CD70 interactions in these patients. We consider it likely that multiple immunomodulators are dysregulated in HIV-infected individuals. Still, if CD27-CD70 interactions are instrumental in driving hyperimmune activation leading to $\mathrm{T}$ cell depletion in HIV infection, it is of interest to consider targeting CD27-CD70 interactions to avoid detrimental consequences of persistent immune activation.

\section{Methods}

Mice. C57BL/6, CD70 Tg ${ }^{15}$, CD27 $7^{-18}$, F5 TCR Tg ${ }^{34}, \mathrm{IFN}^{-} \gamma^{/-}\left(\mathrm{C} 57 \mathrm{BL} / 6-\mathrm{ifn} \mathrm{fm}^{\mathrm{tm} 1 \mathrm{Ts}}\right)^{35}$ mice, all on a C57BL/6 background, were bred in the facilities of the Netherlands Cancer Institute and Sanquin Research under specific pathogen-free conditions. Identification of mutant mice was done by PCR analysis of tail DNA or by FACS analysis of peripheral blood cells. All animal experiments were done according to institutional and national guidelines and approved by the Experimental Animal Committees of the respective institutes.

mAbs. The following antibodies were from PharMingen (San Diego, CA): allophycocyanin-CD3ع (clone 145-2C11), fluorescein isothiocyanate (FITC)-CD4, peridinin chlorophyll protein (PerCP)-CD4 (clone RM4-5), phycoerythrin (PE)-CD8 $\alpha$, PerCP-CD8 $\alpha$ (clone 53-6.7), FITC-CD43 (clone 1B11), PE-CD44 (clone IM7) and FITC-CD62L (clone MEL-14). Anti-CD3ع (clone 145-2C11) and anti-CD70 (clone 3B9) (unpublished data) were purified from hybridoma culture supernatant after standard procedures.

Flow cytometry. Single-cell suspensions were obtained from spleen, lymph nodes (axillary, brachial and inguinal or mesenteric) and thymus by grinding the tissues through nylon sieves. Cells $\left(4 \times 10^{5}\right)$ were collected in 96 -well U-bottomed plates in FACS staining buffer (PBS with $0.5 \%$ bovine serum albumin). All samples were preincubated for $10 \mathrm{~min}$ with anti-CD16-CD32 (Fc block, clone 2.4G2, PharMingen, San Diego, CA) and subsequently stained for $30 \mathrm{~min}$ at $4{ }^{\circ} \mathrm{C}$ with antibodies. After cell-surface staining, intracellular BrdU and Ki-67 staining was done following the manufacturer's instruction with a BrdU-FITC Flow kit and a Ki-67-PE set, respectively (PharMingen). Annexin V and PI staining was done with an APOPTEST-FITC kit (Nexins Research BV, Kattendijk, The Netherlands). FACS analysis was done on a FACSCalibur with Cell Quest software (Becton Dickinson, San Jose, CA).

BrdU labeling. Four-week-old mice were given drinking water containing $\operatorname{BrdU}(0.8$ $\mathrm{mg} / \mathrm{ml}$ ) (Sigma, St. Louis, MO) for 10 days. Mice were killed at 5.5, 6.5, 8.5 and 10.5 weeks of age (that is, $0,1,3$ and 5 weeks after stopping BrdU administration).

Proliferation assay. T cells were purified from mesenteric lymph nodes by negative depletion with rat anti-MHC class II, rat anti-B220, goat anti-rat IgG microbeads (Miltenyi Biotec, Bergisch Gladbach, Germany) and MACS (BS) depletion columns following the manufacturer's instructions. Purified T cells $\left(>90 \% \mathrm{CD}^{+}\right.$, as analyzed by flow cytometry) were cultured in Iscove's modified Dulbecco's medium supplemented with $10 \%$ fetal calf serum and stimulated with $1 \mu \mathrm{g} / \mathrm{ml}$ of PHA $\left(10^{5}\right.$ cells $/$ well, Murex, Lenexa, KS $)$ or $10 \mu \mathrm{g} / \mathrm{ml}$ of anti-CD3 $\varepsilon$ (clone 145-2C11, immobilized). $\left[{ }^{3} \mathrm{H}\right]$ thymidine $(0.4 \mu \mathrm{Ci}$, Amersham International, Little Chalfont, UK) was added for the last $16 \mathrm{~h}$ of a $96-\mathrm{h}$ culture period.

Immunohistochemistry. Hematoxylin-eosin staining and Grocott staining were done on formalin-fixed lung tissue sections following standard procedures.

Antibody treatment. Mice were given anti-murine CD70 (3B9) or control hamster mAb ( $250 \mu \mathrm{g}$ per intraperitoneal injection) twice weekly for a period of 3 weeks. 
Influenza virus infection. F5 TCR Tg and F5 TCR Tg CD70 Tg mice were anesthetized and infected intranasally with $25 \mathrm{HAU}$ of influenza virus strain $\mathrm{A} / \mathrm{NT} / 60 / 68$ for infection. Before (day 0 ) and at day 9 after infection, blood from tail was collected, erythrocytes were lysed and cells were analyzed by flow cytometry.

\section{Acknowledgments}

We thank D. Kioussis (London, UK) for providing us with the F5 Tg mice and E. Eldering,

J. Hamann, R. Lutter and K. A. Reedquist for critically reviewing the manuscript.

Competing interests statement

The authors declare that they have no competing financial interests.

Received 20 August 2002; accepted 29 October 2002.

I. Lander, E.S. et al. Initial sequencing and analysis of the human genome. Nature 409, 860-921 (200I).

2. Locksley, R.M., Killeen, N. \& Lenardo, M.J. The TNF and TNF receptor superfamilies: integrating mammalian biology. Cell 104, 487-50I (200I).

3. Gravestein, L.A. \& Borst, J. Tumor necrosis factor receptor family members in the immune system Semin. Immunol. 10, 423-434 (1998).

4. Screaton, G. \& Xu, X.N.T cell life and death signalling via TNF-receptor family members. Curr. Opin Immunol. 12, 316-322 (2000)

5. Chen, A.I. et al. Ox40-ligand has a critical costimulatory role in dendritic cell:T cell interactions. Immunity II, 689-698 (1999).

6. Kopf, M. et al. OX40-deficient mice are defective in Th cell proliferation but are competent in generating B cell and CTL responses after virus infection. Immunity II, 699-708 (1999).

7. Tan, J.T., Whitmire, J.K., Ahmed, R., Pearson, T.C. \& Larsen, C.P. 4-IBB ligand, a member of the TNF family, is important for the generation of antiviral CD8 T cell responses. J. Immunol. 163 4859-4868 (1999).

8. Hendriks, J. et al. CD27 is required for generation and long-term maintenance of T cell immunity. Nat. Immunol. I, 433-440 (2000).

9. McDermott, M.F. et al. Germline mutations in the extracellular domains of the $55 \mathrm{kDa}$ TNF receptor, TNFRI, define a family of dominantly inherited autoinflammatory syndromes. Cell 97 133-144 (1999).

10. Green, E.A., Eynon, E.E. \& Flavell, R.A. Local expression of TNF- $\alpha$ in neonatal NOD mice promotes diabetes by enhancing presentation of islet antigens. Immunity 9, 733-743 (1998).

1. Mackay, F. et al. Mice transgenic for BAFF develop lymphocytic disorders along with autoimmune manifestations.J. Exp. Med. 190, 1697-1710 (1999).

12. Hintzen, R.Q. et al. Characterization of the human CD27 ligand, a novel member of the TNF gene family.J. Immunol. 152, 1762-1773 (1994).

3. Tesselaar, K., Gravestein, L.A., van Schijndel, G.M., Borst, J. \& van Lier, R.A. Characterization of murine CD70, the ligand of the TNF receptor family member CD27. J. Immunol. I59, 4959-4965 (1997).

14. Oshima, H. et al. Characterization of murine CD70 by molecular cloning and mAb. Int. Immunol. 10 517-526 (1998)
15. Arens, R. et al. Constitutive CD27/CD70 interaction induces expansion of effector-type $T$ cells and results in IFN $\gamma$-mediated B cell depletion. Immunity I5, 80I-8I2 (200I).

16. Harrington, L.E., Galvan, M., Baum, L.G.,Altman, J.D. \& Ahmed, R. Differentiating between memory and effector CD8 T cells by altered expression of cell surface O-glycans.J. Exp. Med. 191, |24I-1246 (2000)

17. Badovinac, V.P., Tvinnereim, A.R. \& Harty, J.T. Regulation of antigen-specific $C D 8^{+} T$ cell homeostasis by perforin and interferon- $\gamma$. Science 290, I354-1358 (2000).

18. Forster, R. et al. CCR7 coordinates the primary immune response by establishing functional microenvironments in secondary lymphoid organs. Cell 99, 23-33 (1999).

19. Ashwell, J.D., Lu, F.W. \& Vacchio, M.S. Glucocorticoids in T cell development and function. Annu. Rev. Immunol. 18, 309-345 (2000).

20. Hintzen, R.Q. et al. Engagement of CD27 with its ligand CD70 provides a second signal for T cell activation. J. Immunol. 154, 2612-2623 (1995).

21. Baum, P.R. et al. Molecular characterization of murine and human OX40/OX40 ligand systems: identification of a human OX40 ligand as the HTLV-I-regulated protein gp34.EMBO J. I3, 3992-400I (1994)

22. Rogers, P.R., Song, J., Gramaglia, I., Killeen, N. \& Croft, M. OX40 promotes Bcl- $\mathrm{x}_{\mathrm{L}}$ and Bcl-2 expression and is essential for long-term survival of CD4 T cells. Immunity 15, 445-455 (200I).

23. Cannons, J.L. et al. 4-IBB ligand induces cell division, sustains survival, and enhances effector function of CD4 and CD8 T cells with similar efficacy. J. Immunol. 167, I313-1324 (2001).

24. Sachsenberg, N. et al. Turnover of $\mathrm{CD} 4^{+}$and $\mathrm{CD} 8^{+} \mathrm{T}$ lymphocytes in HIV-I infection as measured by Ki-67 antigen. J. Exp. Med. 187, 1295-1303 (1998)

25. Kaslow, R.A. et al. Infection with the human immunodeficiency virus: clinical manifestations and their relationship to immune deficiency. A report from the Multicenter AIDS Cohort Study. Ann. Intern. Med. 107, 474-480 (1987)

26. Roederer, M. et al. CD8 naive T cell counts decrease progressively in HIV-infected adults. J. Clin. Invest. 95, 206I-2066 (1995)

27. Clerici, M. et al. Detection of three distinct patterns of $T$ helper cell dysfunction in asymptomatic, human immunodeficiency virus-seropositive patients. Independence of $\mathrm{CD}^{+}$cell numbers and clinical staging. J. Clin. Invest. 84, 1892-1899 (1989).

28. Fauci, A.S. The human immunodeficiency virus: infectivity and mechanisms of pathogenesis. Science 239, 617-622 (1988).

29. Zinkernagel, R.M. \& Hengartner, H. T-cell-mediated immunopathology versus direct cytolysis by virus: implications for HIV and AIDS. Immunol. Today 15, 262-268 (1994).

30. Hazenberg, M.D. et al. Increased cell division but not thymic dysfunction rapidly affects the T-cell receptor excision circle content of the naive T cell population in HIV-I infection. Nat. Med. 6 1036-1042 (2000)

31. Grossman, Z., Meier-Schellersheim, M., Sousa, A.E.,Victorino, R.M. \& Paul,W.E. CD4 ${ }^{+}$T-cell depletion in HIV infection: are we closer to understanding the cause? Nat. Med. 8, 319-323 (2002).

32. Wolthers, K.C. et al. Increased expression of CD80, CD86 and CD70 on T cells from HIV- infected individuals upon activation in vitro: regulation by $\mathrm{CD}^{+} \mathrm{T}$ cells. Eur. J. Immunol. 26, 1700-1706 (1996).

33. Appay,V. et al. Characterization of CD4+ CTLs ex vivo. J. Immunol. 168, 5954-5958 (2002).

34. Mamalaki, C. et al. Positive and negative selection in transgenic mice expressing a T-cell receptor specific for influenza nucleoprotein and endogenous superantigen. Dev. Immunol. 3, 159-174 (1993)

35. Dalton, D.K. et al. Multiple defects of immune cell function in mice with disrupted interferon- $\gamma$ genes. Science 259, 1739-1742 (1993). 


\section{Lethal T cell immunodeficiency induced by chronic costimulation via CD27-CD70 interactions}

Kiki Tesselaar, Ramon Arens, Gijs M.W. van Schijndel, Paul A. Baars, Martin A. van der Valk, Jannie Borst, Marinus H.J. van Oers and René A.W. van Lier

Nat. Immunol. 4, 49-54 (2003).

Panel labels in the legend to Figure 2 were incorrect. The corrected legend is printed below.

Figure 2. T cell cellularity and phenotype in CD70 Tg mice. Absolute numbers of $\mathrm{CD}^{+} \mathrm{T}$ cells in PLNs (a) and spleen (b) from WT and CD70 Tg mice aged 4, 8, 13 and 20 weeks were determined. T cell numbers were calculated by multiplying the number of mononuclear cells with the percentage of $\mathrm{CD}^{+} \mathrm{T}$ cells, as determined by flow cytometry. (c) Thymic cellularity was determined by counting lymphocyte numbers of WT and CD70 Tg mice at the indicated ages. Mean \pm s.d. data from four to six mice are shown. Differences between the mean values for WT and CD70 Tg at the indicated ages were considered significant ( $*$ ) if $P<0.05$ (by Student's $t$-tests). (d) Phenotypes of CD4 ${ }^{+}$and CD $8^{+}$ splenic $\mathrm{T}$ cells determined by flow cytometry. Naive $\mathrm{T}$ cells were defined as $\mathrm{CD} 44^{\text {neg/lo }} \mathrm{CD} 62 \mathrm{~L}^{\text {hi }}$; effector-memory cells were defined as $\mathrm{CD} 44^{\mathrm{hi}} \mathrm{CD} 62 \mathrm{~L}^{\mathrm{neg}}$. The percentages of cells in each quadrant are indicated.

corresponding author details:

Kiki Tesselaar

K_Tesselaar@CLB.nl

phone: 0031205123314

fax: 0031205123310 